\title{
Burden of Insomnia and Sleep Disturbances and the Impact of Sleep Treatments in Patients with Probable or Possible
}

\section{Alzheimer's Disease: A Structured Literature Review}

\author{
Ruth Benca ${ }^{\mathrm{a}}$, W. Joseph Herring ${ }^{\mathrm{b}}$, Rezaul Khandker ${ }^{\mathrm{b}}$ and Zaina P. Qureshi ${ }^{\mathrm{b}, *}$ \\ ${ }^{\mathrm{a}}$ University of California, Irvine, CA, USA \\ ${ }^{\mathrm{b}}$ Merck \& Co., Inc., Kenilworth, NJ, USA
}

Accepted 3 December 2021

Pre-press 1 February 2022

\begin{abstract}
.
Background: Sleep disturbances are frequent in Alzheimer's disease (AD). This review summarizes the impact of sleep disturbances on $\mathrm{AD}$ patients and their caregivers and the effects of currently available sleep therapies.

Methods: Published studies (January 1985-March 2020) assessing the burden associated with insomnia/sleep disturbances in the $\mathrm{AD}$ population and insomnia treatment effects were identified by searching PubMed, Embase and Cochrane Library and screened against inclusion criteria.

Findings: This review included 58 studies which assessed patient and caregiver burden, institutionalization, and insomnia treatments in AD patients with sleep disturbances. Sleep disturbances were associated with worse cognition, functional ability, and behavioral and neuropsychological functioning, including increased depression and anxiety. Health status and quality of life of both patients and caregivers were reduced in the presence of sleep disturbances, with caregiver burden driven largely by disruptive nocturnal behaviors including nighttime awakenings and wanderings. Sleep disturbances were also associated with institutionalization. Although significant associations between sleep problems and clinical outcomes were apparent, there was generally no control for other influencing factors (e.g. cognitive status). With respect to insomnia treatments, bright light, and behavioral therapies as well as drugs such as trazodone, risperidone and suvorexant showed some promise in $\mathrm{AD}$ patients, but studies were primarily small and limited data were available, particularly in regard to insomnia treatment effects on associated clinical burden.

Interpretation: Sleep disturbances are a significant problem for AD patients and caregivers. They are associated with behavioral and psychological problems and cognitive decline and impose a burden on caregivers, but remain poorly characterized and under-researched. As the global population is aging and $\mathrm{AD}$ is on the rise, data from larger, prospective trials are required to fully understand the clinical correlates of sleep disturbances and the impact of insomnia treatments on AD patients and their caregivers.
\end{abstract}

Keywords: Insomnia, Alzheimer's disease, sleep disturbances, literature review, caregiver burden, clinical burden, institutionalization, treatment guidelines

\footnotetext{
${ }^{*}$ Correspondence to: Zaina P. Qureshi, Director, Immuno$\operatorname{logy} \&$ Neuroscience, Center for Observational and Real-World
} 


\section{INTRODUCTION}

Alzheimer's disease (AD) is a progressive neurodegenerative disease, characterized by continuing cognitive decline and memory loss; [1] it accounts for $60 \%$ to $80 \%$ of dementia cases in adults $>65$ years of age. With an aging global population, the AD population is expected to triple over the next 40 years, to over 13 million cases [2].

$\mathrm{AD}$ is associated with significant healthcare costs and resource utilization, particularly when patients require admission to care facilities [3]. The behavioral symptoms of dementia, including disturbed sleep, nighttime awakenings and wanderings place a substantial burden on family and caregivers, and lead to the early institutionalization of AD patients $[2,4]$.

Insomnia is characterized by difficulty initiating or maintaining sleep among individuals with adequate opportunity to sleep and is associated with daytime consequences, such as an inability to perform daily activities [5]. Insomnia symptoms and sleep disturbances (collectively referred to in this manuscript as sleep problems) increase with age and are common in $\mathrm{AD}$ patients, with a prevalence of $>50 \%$ [6-8]. $\mathrm{AD}$ patients also experience more severe symptoms of insomnia and sleep disturbances, such as increased sleep latency and reduced sleep maintenance, as well as progressive deterioration and instability of circadian rhythms, compared to older adults without $\mathrm{AD}$ $[9,10]$. Moreover, insomnia is also a risk factor for $\mathrm{AD},[11]$ and a bidirectional relationship is thought to exist between poor sleep and AD pathology [12].

Despite the high prevalence and substantial disease burden of insomnia in $\mathrm{AD}$ patients, including negative impacts of insomnia symptoms on mental and physical health, quality of life (QoL) and functional ability, treatment options for this patient population are limited. Benzodiazepine receptor agonists are associated with an increased risk of falls, fractures, and clinically significant impairments in balance and cognition upon awakening [13]. The American Geriatrics Society strongly recommends against the use of benzodiazepines and related nonbenzodiazepines in elderly patients [14]. Moreover, current non-pharmacological treatments such as cognitive behavioral therapy for insomnia (CBT-I) may not be effective as AD patients may be unwilling or unable to participate in therapy [5]. Due to the limitations of non-pharmacological and pharmacological treatments for the management of insomnia in $\mathrm{AD}$ patients there is a significant unmet need. Currently, one medication (suvorexant) has been specifically approved for the treatment of insomnia in $\mathrm{AD}$ patients by the US Food and Drug Administration (FDA).

This literature review aims to summarize the clinical, economic, and QoL impact of insomnia and sleep disturbances on patients and their caregivers, as well as the abilities of currently available therapies to treat sleep problems and reduce their impacts in this population.

\section{METHODS}

\section{Search strategy}

We searched Publisher Medline (PubMed), Excerpta Medica Database (Embase) and Cochrane Library for articles published between January 1985, and March 2020, using combinations of keywords and Medical Subject Headings (MeSH) terms pertaining to $\mathrm{AD}$, insomnia/sleep disturbances, disease and caregiver burden, healthcare resource utilization (HCRU), treatment patterns and guidelines (Table S1 through Table S9 in the supplementary appendix). Reference lists of included publications were reviewed to identify relevant publications not captured through the database searches.

\section{Criteria for study inclusion/exclusion}

Eligible studies and reviews met the following inclusion criteria: (1) AD patients with insomnia, or sleep disorders, disturbances or dysfunctions (specific sleep disorder/disturbance not reported); (2) disease burden (QoL, functional status, cognitive functioning, behavioral symptoms, and impact on daily living) and caregiver burden outcomes, HCRU, treatment patterns and guidelines; (3) peer-reviewed; (4) English language. Publications were excluded if they included only sleep disorders other than insomnia such as hypersomnia, parasomnia, excessive daytime sleepiness, and obstructive sleep apnea. Where studies were published as both research articles and conference abstracts, the latter were excluded. Full PICOS criteria are reported in the appendix (Table S10).

\section{Data extraction and synthesis}

Data extraction was performed by one reviewer and cross-checked by a second reviewer using standardized forms to ensure accuracy. Data from the extracted publications were qualitatively synthesized to summarize the findings of the literature review. 


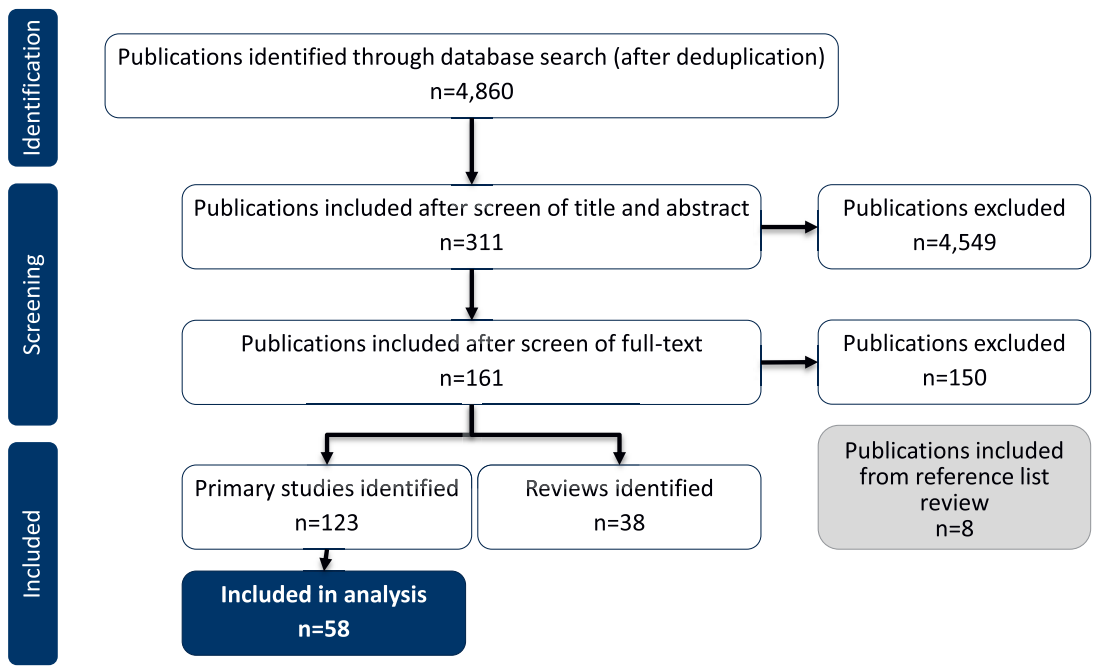

Fig. 1. Study flow diagram.

\section{RESULTS}

The search identified 4,860 articles, from which 311 were taken forward to full text review. After screening the full texts against the eligibility criteria, 161 publications were included (123 primary studies and 38 reviews). Eight more publications were included through an additional review of the reference lists (Fig. 1). The majority of publications were excluded for not reporting data for AD patients with insomnia/sleep disturbances.

Only studies characterizing the clinical and caregiver burden of sleep disturbances in patients reported to have $\mathrm{AD}$ (including probable or possible $\mathrm{AD}$ ) were included in this review (58 studies). Clinical burden included the impact of sleep disturbances on patients' health and wellbeing. Studies reporting prevalence and incidence data for sleep disturbances in $\mathrm{AD}$ patients and those reporting data for mild cognitive impairment (MCI) were not included in this review (65 studies). To avoid duplication, only primary studies are included in the results. Relevant reviews identified have been included in the Discussion.

The majority of included studies reported data for non-specific sleep disturbances in $\mathrm{AD}$, with fewer evaluating insomnia specifically. Table 1 summarizes the included studies and sleep problem definitions.

\section{Clinical burden of sleep disturbances in $A D$ and impact on $Q o L$}

Sleep disturbances were not consistently characterized across studies. Many relied on the
Neuropsychiatric Inventory (NPI), which has a single item to screen for the presence of sleep disturbed behaviors, that incorporates symptoms of awakening the caregiver at night, waking early in the morning and daytime napping, and rates the frequency, severity and distress $[4,29,72]$. An important caveat is that there is insufficient clinical description of the nature of the sleep problems in most studies, and there is not a standardized tool for assessing sleep in AD patients. Despite this limitation, sleep problems in AD patients were associated with impairments across several domains (Table 2). No studies specifically assessed the clinical burden of insomnia in AD.

Cross-sectional studies found significant negative correlations between Mini-Mental State Examination (MMSE) scores and sleep disturbances, suggesting that sleep disturbances are associated with worse cognition [29, 71]. Similar associations were reported for patients' functional impairment [4, 19, 28, 29, 51, 71]. Associations between sleep disturbances and decreased cognitive functioning were reported in five of the nine studies identified (Table 2) [23, 25, 28, 29, 54, 58, 63, 70, 71]. Similarly, associations between sleep disturbances and daily functioning were reported in 10 of the 14 studies identified (Table 2) [4, 19, 28, 29, 47, 51, 58, 68, 70, 71]. Even studies that did not find an association between cognition or functional status and sleep problems (e.g., de Oliveira et al., and Moran et al.) reported sleep problems associated with behavioral disturbances, as defined by the NPI or BEHAVE-AD $[25,54]$. Moran et al. found no significant cognitive or functional impairment differences between 
Table 1

Included studies and definitions used for cognitive impairment and sleep problems

\begin{tabular}{|c|c|c|c|c|c|}
\hline Study & Country & Setting & Sample size & Diagnosis & Definition of sleep problem \\
\hline Allegri, 2006 [15] & Argentina & $\begin{array}{l}\text { Clinic/hospital (19 } \\
\text { patients were } \\
\text { institutionalized) }\end{array}$ & 82 & Probable or possible $\mathrm{AD}$ & $\begin{array}{l}\text { Sleep disturbances, determined using a Spanish version of the NPI } \\
\text { (unusual behavior at nighttime) }\end{array}$ \\
\hline $\begin{array}{l}\text { Ancoli-Israel, } 2003 \\
{[16]^{*}}\end{array}$ & US & Nursing home & 92 & $\begin{array}{l}\text { Probable or possible } \\
\text { severe } \mathrm{AD}\end{array}$ & $\begin{array}{l}\text { Studied effects of treatment on sleep and circadian activity } \\
\text { rhythms, measured via wrist actigraphy }\end{array}$ \\
\hline Baek, 2019 [17] & South Korea & $\begin{array}{l}\text { National Health } \\
\text { Insurance Service }\end{array}$ & $\begin{array}{l}2,796,871 \text { insomnia } \\
\text { patients of whom } \\
138,270 \text { had newly } \\
\text { diagnosed } \mathrm{AD}\end{array}$ & $\begin{array}{l}\text { Probable or possible AD } \\
\text { or VD }\end{array}$ & Diagnosed insomnia (ICD-10 codes) \\
\hline Bianchetti, 1995 [18] & Italy & $\begin{array}{l}\text { Discharged from } \\
\text { dementia unit }\end{array}$ & 86 & Probable or possible $\mathrm{AD}$ & Insomnia recorded at discharge (not defined) \\
\hline Bliwise, 1995 [19] & US & Special AD care unit & 47 & Probable or possible AD & $\begin{array}{l}\text { Moderate and severe sleep disturbances defined by } \geq 1 \text { or } \geq 2 \\
\text { observations of wakefulness during night, respectively }\end{array}$ \\
\hline Brusco, $1999[20]^{*}$ & Argentina & Outpatients & $\begin{array}{l}41 \text { (retrospective } \\
\text { analysis including } \\
\text { only AD: } 14)\end{array}$ & $\begin{array}{l}\text { Probable or possible } \mathrm{AD} \\
\text { or VaD }\end{array}$ & $\begin{array}{l}\text { Sleep disorder/sleep disturbances reported via sleep logs } \\
\text { (caregiver-reported) }\end{array}$ \\
\hline Camargos, $2014[21]^{*}$ & Brazil & $\begin{array}{l}\text { Community/ } \\
\text { outpatients }\end{array}$ & 30 & Probable or possible AD & $\begin{array}{l}\text { Sleep disturbances: nighttime insomnia/sleep complaints reported } \\
\text { after AD diagnosis, } \geq 2 \text { sleep disorders on NPI. }\end{array}$ \\
\hline Camargos, 2015 [22] & Brazil & Hospital outpatients & 41 & Probable or possible $\mathrm{AD}$ & $\begin{array}{l}\text { Sleep disturbances causing emotional distress to caregivers (score } \\
\text { of } \geq 1 \text { on NPI; caregiver-reported) and sleep profile determined } \\
\text { via actigraphy }\end{array}$ \\
\hline Chew, 2019 [23] & Singapore & $\begin{array}{l}\text { Hospital memory } \\
\text { clinic }\end{array}$ & 64 & $\begin{array}{l}\text { Probable or possible AD } \\
\text { with MCI }\end{array}$ & Sleep duration, defined by the PSQI \\
\hline Colenda, $1997[24]^{*}$ & US & Community-based & 5 & Probable or possible $\mathrm{AD}$ & $\begin{array}{l}\text { Disturbed circadian rest-activity cycles (caregiver-reported frequent } \\
\text { nighttime awakenings and daytime napping) }\end{array}$ \\
\hline de Oliveira, 2014 [25] & Brazil & $\begin{array}{l}\text { Outpatient neurology } \\
\text { clinic }\end{array}$ & 217 & Probable or possible AD & Unsatisfied sleep defined by patient (confirmed by caregiver) \\
\hline Donaldson, 1998 [26] & UK & Home & 100 & Probable or possible AD & $\begin{array}{l}\text { Sleep disturbances rated using a subsection of the MOUSEPAD } \\
\text { (caregiver-reported) }\end{array}$ \\
\hline Dowling, 2005 [27]* & US & Care facility & 46 & $\begin{array}{l}\text { Probable or possible } \\
\text { severe AD }\end{array}$ & $\begin{array}{l}\text { Rest-activity disruptions, including insomnia, frequent nighttime } \\
\text { awakenings, wandering at night, unusually early morning } \\
\text { awakenings, "sundowning," and excessive daytime sleepiness }\end{array}$ \\
\hline Escudero, 2019 [28] & Colombia & $\begin{array}{l}\text { Hospital-based } \\
\text { memory clinic }\end{array}$ & 47 & Probable or possible $\mathrm{AD}$ & Sleep problems defined using the CUSPAD and NPI \\
\hline $\begin{array}{l}\text { Garcia-Alberca, } 2013 \\
\text { [29] }\end{array}$ & Spain & Outpatient clinic & 125 & Probable or possible AD & $\begin{array}{l}\text { Sleep disturbances determined using the sleep disorders item from } \\
\text { the NPI; caregiver-reported }\end{array}$ \\
\hline Gehrman, $2009[30]^{*}$ & US & Nursing homes & 41 & Probable or possible AD & Various sleep parameters assessed actigraphically \\
\hline Gehrman, 2018 [31] & US & Clinic/center & 130 & Probable or possible AD & $\begin{array}{l}\text { Sleep disturbances defined by caregiver ratings; defined as a sleep } \\
\text { latency }>30 \mathrm{~min}, \geq 3 \text { nocturnal awakenings per night, frequency } \\
\text { of nocturnal wandering }>1 \text { per month, frequency of loud snoring } \\
>2 \text { per week, and/or spending }>1 \mathrm{~h} \text { asleep in day }\end{array}$ \\
\hline
\end{tabular}




\begin{tabular}{|c|c|c|c|c|c|}
\hline Grace, 2000 [32] & UK & Clinic/hospital & 37 (20 with AD) & $\begin{array}{l}\text { Probable or possible AD } \\
\text { or DLB }\end{array}$ & Sleep disturbances defined using the ESS and PSQI \\
\hline Hart, 2003 [33] & NR & Memory clinic & 100 & Probable or possible AD & Sleep disturbances defined using the NPI (caregiver-reported) \\
\hline $\begin{array}{l}\text { Hannesdottir, } 2013 \\
{[34]^{*}}\end{array}$ & US & NR & 81 & $\begin{array}{l}\text { Probable or possible AD } \\
\text { and MCI }\end{array}$ & Not defined; study assessed sleep improvements in AD \\
\hline Herring, $2020[35]^{*}$ & $\begin{array}{l}\text { Canada, Finland, } \\
\text { Italy, New } \\
\text { Zealand, Peru, } \\
\text { South Korea, } \\
\text { UK, US }\end{array}$ & $\begin{array}{l}\text { Memory/research } \\
\text { clinics }\end{array}$ & 277 & Probable or possible $\mathrm{AD}$ & $\begin{array}{l}\text { Insomnia; meeting DSM- } 5 \text { diagnostic criteria for insomnia and } \\
\text { confirmed by mean total sleep time }<6 \text { h over screening and } \\
\text { baseline PSG (neither night }>6.5 \mathrm{~h} \text { ) }\end{array}$ \\
\hline Ishikawa, $2016[36]^{*}$ & Japan & Hospital/clinic & 12 & Probable or possible AD & $\begin{array}{l}\text { Sleep problems/sleep architecture changes (subjective and } \\
\text { objective measures) }\end{array}$ \\
\hline Kabeshita, 2017 [37] & Japan & $\begin{array}{l}\text { Seven psychiatry and } \\
\text { neurology centers }\end{array}$ & 684 & Probable or possible AD & Sleep disturbances defined using the NPI \\
\hline Kazui, 2016 [38] & Japan & $\begin{array}{l}\text { Outpatients from } \\
\text { multiple } \\
\text { centers/hospitals }\end{array}$ & $\begin{array}{l}1,598(1,091 \text { with } \\
\text { AD) }\end{array}$ & $\begin{array}{l}\text { Probable or possible AD, } \\
\text { DLB, VaD, and FTLD }\end{array}$ & Sleep disturbances defined using the NPI (caregiver-reported) \\
\hline Kim, 2017 [39] & NR & NR & 46 & $\begin{array}{l}\text { Probable or possible AD } \\
\text { (early stage) }\end{array}$ & Sleep problems defined using the NPI \\
\hline La, $2019[40]^{*}$ & NR & Memory center & 50 & $\begin{array}{l}\text { Probable or possible AD, } \\
\text { MCI or non-impaired }\end{array}$ & $\begin{array}{l}\text { Sleep disturbances (absent or present) documented by a physician; } \\
\text { insomnia defined separately }\end{array}$ \\
\hline Lebrija, 2016 [41] & Mexico & Hospital/clinic & 64 & Probable or possible $\mathrm{AD}$ & Sleep disturbance defined using the SDI and NPI \\
\hline Lee, $2018[42]^{*}$ & Korea & $\begin{array}{l}\text { Home (study specified } \\
\text { that 'home-based' } \\
\text { light treatment was } \\
\text { used) }\end{array}$ & 10 & $\begin{array}{l}\text { Mild or moderate } \\
\text { probable or possible AD }\end{array}$ & Insomnia symptoms $\geq 3$ times per week and/or PSQI score of $\geq 5$ \\
\hline Leger, 2017 [43] & $\begin{array}{l}\text { France, Germany, } \\
\text { Spain, Italy, } \\
\text { Portugal, } \\
\text { Poland, US, } \\
\text { Canada, } \\
\text { Australia }\end{array}$ & Outpatients & 208 & $\begin{array}{l}\text { Mild to moderate } \\
\text { probable or possible AD }\end{array}$ & Sleep disturbances (measured by actigraphy) \\
\hline Leng, 2020 [44] & China & $\begin{array}{l}\text { Outpatient geriatric } \\
\text { clinic }\end{array}$ & $\begin{array}{l}221 \text { (AD: 17, MCI: } \\
\text { 67, subjective } \\
\text { cognitive decline: } \\
\text { 91, non-impaired: } \\
\text { 46) }\end{array}$ & $\begin{array}{l}\text { Probable or possible AD, } \\
\text { MCI, subjective } \\
\text { cognitive decline, } \\
\text { non-impaired }\end{array}$ & $\begin{array}{l}\text { Sleep disturbances defined using the PSQI. Assessed over four } \\
\text { weeks, based on a } 0-3 \text { scale for each item }\end{array}$ \\
\hline Lukovits, 1992 [45] & US & $\begin{array}{l}\text { Long-term care } \\
\text { facility }\end{array}$ & 33 & $\begin{array}{l}\text { End stage probable or } \\
\text { possible AD }\end{array}$ & Sleep disturbances defined via caregiver questionnaire \\
\hline McCarten, 1995 [46]* & US & Clinic ward & 7 & Probable or possible AD & $\begin{array}{l}\text { Sleep disruption; caregivers' complaint that patients were } \\
\text { frequently up at night }\end{array}$ \\
\hline
\end{tabular}


Table 1

(Continued)

\begin{tabular}{|c|c|c|c|c|c|}
\hline Study & Country & Setting & Sample size & Diagnosis & Definition of sleep problem \\
\hline McCurry, 1999 [47] & US & Community-based & 205 & Probable or possible AD & $\begin{array}{l}\text { Sleep problems defined by the rating of seven different sleep } \\
\text { behaviors from caregivers }\end{array}$ \\
\hline McCurry, 2003 [48]* & NR & Community-based & 22 & Probable or possible AD & $\begin{array}{l}\text { Sleep disturbances ( } \geq 1 \text { sleep problem on the NPI occurring } \geq 3 \\
\text { times a week) }\end{array}$ \\
\hline McCurry, 2004 [49] & US & Community-based & 153 & Probable or possible AD & $\begin{array}{l}\text { Sleep disturbances: multiple awakenings at night } \\
\text { (caregiver-reported) }\end{array}$ \\
\hline McCurry, 2005 [50]* & US & Community-based & 36 & Probable or possible AD & $\begin{array}{l}\text { Sleep problems ( } \geq 2 \text { sleep problems on NPI nighttime behavior } \\
\text { scale occurring } \geq 3 \text { times per week; caregiver-reported) }\end{array}$ \\
\hline McCurry, 2006 [51] & US & Community-based & 46 & Probable or possible AD & $\begin{array}{l}\text { Sleep problems; } \geq 2 \text { sleep problems on the NPI that occur } \geq 3-6 \\
\text { times a week (caregiver-reported), objective sleep measures also } \\
\text { used in study (actigraph) }\end{array}$ \\
\hline McCurry, $2011[52]^{*}$ & US & Community-based & 132 & Probable or possible AD & $\begin{array}{l}\text { Sleep problems; } \geq 2 \text { sleep problems occurring several times a week, } \\
\text { measured by the } 7 \text {-item SDI }\end{array}$ \\
\hline Meguro, 2004 [53] & Japan & Nursing home & 34 & Probable or possible AD & $\begin{array}{l}\text { Disturbed sleep/wake patterns with wandering; patients manifested } \\
\text { wandering behavior or aggressiveness for more than } 4 / 7 \text { days } \\
\text { (caregiver-reported via written criteria, and BEHAVE-AD) }\end{array}$ \\
\hline Moran, 2005 [54] & Ireland & $\begin{array}{l}\text { Recruited from } \\
\text { memory/aging } \\
\text { center }\end{array}$ & 224 & Probable or possible AD & $\begin{array}{l}\text { Sleep disturbances, defined using the question about diurnal rhythm } \\
\text { disturbance on the BEHAVE-AD questionnaire } \\
\text { (informant-reported) }\end{array}$ \\
\hline Mulin, 2011 [55] & US & $\begin{array}{l}\text { Recruited from } \\
\text { memory/AD centers }\end{array}$ & 103 & $\begin{array}{l}\text { Mild or moderate } \\
\text { probable or possible AD }\end{array}$ & Sleep disturbance measured via actigraph and caregiver reports \\
\hline Okuda, 2019 [56] & Japan & $\begin{array}{l}\text { Recruited from } \\
\text { Japanese register }\end{array}$ & 496 & $\begin{array}{l}\text { Mild to moderate } \\
\text { probable or possible } \mathrm{AD}\end{array}$ & $\begin{array}{l}\text { Clinically diagnosed insomnia: } 30.4 \% \text {; circadian rhythm sleep } \\
\text { disorder: } 22.2 \% \text {; parasomnia: } 7.9 \% \text {; narcolepsy: } 5.4 \% \text {; sleep } \\
\text { apnea: } 5.4 \% \text {; other sleep difficulties: } 5.4 \% \text {; no diagnosis: } 49.4 \% \text {; } \\
\text { and SDI (Japanese version) }\end{array}$ \\
\hline Ownby, 2010 [57] & US & Clinic & 395 & Probable or possible AD & Sleep problems (caregiver-reported) \\
\hline Ownby, 2014 [58] & US & $\begin{array}{l}\text { University-based } \\
\text { memory disorder } \\
\text { clinic }\end{array}$ & 344 & Probable or possible AD & Sleep disturbance (caregiver-reported) \\
\hline Pang, $2002[59]$ & $\begin{array}{l}\text { US, Taiwan, Hong } \\
\text { Kong }\end{array}$ & $\begin{array}{l}\text { Clinic/hospital/research } \\
\text { centers }\end{array}$ & $\begin{array}{l}289 \text { (US: 169; Taiwan: } \\
\text { 89; Hong Kong: } 31 \text { ) }\end{array}$ & Probable or possible AD & Sleep problems defined using the NPI (caregiver-reported) \\
\hline Petrescu, $2019[60]^{*}$ & Romania & Inpatients & 43 & Probable or possible AD & $\begin{array}{l}\text { Sleep disturbances/insomnia symptoms defined from subjective } \\
\text { patient and family caretaker interview and objective nursing sleep } \\
\text { log reviews }\end{array}$ \\
\hline Ribeiro, 2018 [61] & Brazil & $\begin{array}{l}\text { Outpatient neurology } \\
\text { clinic }\end{array}$ & NR & $\begin{array}{l}\text { Mild and moderate } \\
\text { probable or possible AD }\end{array}$ & Sleep disturbances, defined using AIS and ESS \\
\hline
\end{tabular}




\begin{tabular}{|c|c|c|c|c|c|}
\hline Scoralick, 2017 [62]* & Brazil & Community & 24 & Probable or possible AD & $\begin{array}{l}\text { Sleep disorders established based on caregivers' emotional distress } \\
\text { per the sleep and nighttime behavior item of NPI }(\text { score } \geq 2)\end{array}$ \\
\hline Shin, 2014 [63] & South Korea & Dementia clinic & $\begin{array}{l}117 \text { ( } 63 \mathrm{AD} \text { and } 54 \\
\text { matched } \\
\text { non-demented } \\
\text { controls [including } \\
42 \text { with } \mathrm{MCI}] \text { ) }\end{array}$ & Probable or possible $\mathrm{AD}$ & $\begin{array}{l}\text { Subjective sleep problems assessed via the Korean version of the } \\
\text { PSQI (problems present during the previous month) }\end{array}$ \\
\hline Simoncini, 2015 [64]* & Italy & Nursing homes & 129 & $\begin{array}{l}\text { Probable or possible AD } \\
\text { and MCI }\end{array}$ & Primary and secondary insomnia defined using the PSQI \\
\hline Singer, $2003[65]^{*}$ & US & $\begin{array}{l}\text { Clinics and long-term } \\
\text { care facilities }\end{array}$ & 157 & Probable or possible $\mathrm{AD}$ & $\begin{array}{l}\text { Nighttime sleep disturbance } \\
\text { Average of }<7 \mathrm{~h} \text { total time immobile per night between } 8 \mathrm{pm} \text { and } \\
\text { 8am over one week (actigraph) plus } \geq 2 \text { episodes of nighttime } \\
\text { behaviors (SDI; caregiver-reported) }\end{array}$ \\
\hline Stahl, $2004[66]^{*}$ & $\begin{array}{l}\text { US, Europe, } \\
\text { Canada }\end{array}$ & NR & $\begin{array}{l}1,698 \text { (across three } \\
\text { RCTs) }\end{array}$ & $\begin{array}{l}\text { Mild to moderate } \\
\text { probable or possible } \mathrm{AD}\end{array}$ & Insomnia/sleep problems derived from physician verbatim accounts \\
\hline $\begin{array}{l}\text { Taemeeyapradit, } 2014 \\
\text { [67] }\end{array}$ & Thailand & Hospital & 158 & $\begin{array}{l}\text { Probable or possible } \mathrm{AD} \text {, } \\
\text { mixed VaD and } \\
\text { probable or possible } \\
\mathrm{AD} \text {, unspecified } \\
\text { dementia }\end{array}$ & $\begin{array}{l}\text { Sleep problems defined using a Thai version of the NPI } \\
\text { (caregiver-reported) }\end{array}$ \\
\hline Tractenberg, 2003 [4] & US & NR & 104 & Probable or possible AD & $\begin{array}{l}\text { Sleep disturbances: }<7 \mathrm{~h} \text { of nighttime sleep during the } 2-3 \text { weeks } \\
\text { prior to the study and/or } \geq 2 \text { nighttime awakenings within the } \\
\text { previous } 2 \text { weeks (SDI, caregiver-reported; actigraphy) }\end{array}$ \\
\hline $\begin{array}{l}\text { Tractenberg, } 2005 \\
\text { [68] }\end{array}$ & US & NR & $\begin{array}{r}662(\mathrm{AD}: 263 \\
\text { control: } 399)\end{array}$ & $\begin{array}{l}\text { Probable or possible AD } \\
\text { and non-demented } \\
\text { elderly cohort }\end{array}$ & $\begin{array}{l}\text { Sleep disturbance, defined using the SDSQ and reports of 'usual' } \\
\text { bed and wake times }\end{array}$ \\
\hline Wade, $2014[69]^{*}$ & $\mathrm{UK} / \mathrm{US}$ & Outpatients & 80 & $\begin{array}{l}\text { Mild to moderate } \\
\text { probable or possible } \mathrm{AD}\end{array}$ & $\begin{array}{l}\text { Insomnia, defined as PSQI } \geq 6 \text { (PSQI completed by investigator } \\
\text { with the caregiver or patient; caregiver report prioritized) }\end{array}$ \\
\hline Yin, $2015[70]^{*}$ & China & Clinic/hospital & 156 & $\begin{array}{l}\text { Mild to moderate } \\
\text { probable or possible } \mathrm{AD}\end{array}$ & $\begin{array}{l}\text { Sleep disturbances defined as }>2 \text { awakenings during the night } \\
\text { (caregiver-reported) and assessed and confirmed by PSG }\end{array}$ \\
\hline Zhou, 2019 [71] & China & Neurology clinic & $\begin{aligned} 176(\mathrm{AD} & =84 \\
\text { control } & =92)\end{aligned}$ & $\begin{array}{l}\text { Probable or possible } \mathrm{AD} \\
\text { and negative controls }\end{array}$ & Sleep disturbances defined using the PSQI \\
\hline
\end{tabular}

AD, Alzheimer's disease; AIS, Athens Insomnia Scale; BEHAVE-AD, Behavioral Pathology in Alzheimer's Disease; CUSPAD, Columbia University Scale for Psychopathology in Alzheimer's Disease; DLB, Dementia with Lewy bodies; DSM-5, Diagnostic and Statistical Manual of Mental Disorders, Fifth Edition; ESS, Epworth Sleepiness Scale; ICD, International Classification of Diseases; MCI, Mild Cognitive Impairment; MOUSEPAD, Manchester and Oxford Scale for Psychopathological Assessment in Dementia; NPI, Neuropsychiatric Inventory; NR, not reported; PSG, polysomnography; PSQI, Pittsburgh Sleep Quality Index; SDI, Sleep Disorders Inventory; SDSQ, sleep diary-derived sleep quality measure; UK, United Kingdom; US, United States; VaD, vascular dementia. 
Table 2

Studies reporting association between sleep disturbances and clinical burden in AD patients

\begin{tabular}{|c|c|}
\hline Author & Relevant objectives assessed \\
\hline Bliwise, 1995 [19] & $\begin{array}{l}\text { The impact of the severity of AD on } \\
\text { behaviorally defined sleep } \\
\text { disturbances }\end{array}$ \\
\hline Ownby, 2014 [58] & $\begin{array}{l}\text { Subtypes of sleep disturbance in } \\
\text { patients with } \mathrm{AD} \text {, and the relation } \\
\text { to patient characteristics }\end{array}$ \\
\hline McCurry, 1999 [47] & $\begin{array}{l}\text { Frequency, predictors and impact of } \\
\text { sleep problems in AD patients }\end{array}$ \\
\hline
\end{tabular}
Clinical outcome results

Greater functional impairment (ADL) was associated with moderately disturbed sleep; no significant correlation was observed between severe sleep disturbances and functional impairment (ADL).

Both the moderate and severe sleep groups had worse cognitive function (MMSE), lower functional status (BDRC), and higher depression scores (CSDD) versus the normal sleep group.

Numerically greater memory (RMBPC) impairment, humanistic burden (BDRS) scores and depression (RMBPC) with increased frequency of sleep disturbances (defined by caregivers).

Prevalence OR: 1.6 for 3-point functional status (BDRS) score change in patients with sleep disturbance in past week.

Tractenberg, 2003 [4] Efficacy of the Sleep Disorders Inventory (SDI) for assessing symptoms of sleep disturbance/disorder

Tractenberg, $2005 \quad$ Prevalence rates of sleep disturbance [68] symptoms in those with possible $\mathrm{AD}$, and a normal elderly control group, and the association of cognitive status with greater prevalence, worse symptomatology, or a different range of symptoms.

McCurry, 2006 [51] Impact of higher \% sleep on (caregivers' reports of sleep disturbances in persons with $\mathrm{AD}$ and actigraph records of patients' sleep-wake activity) on clinical outcomes.

Garcia-Alberca, 2013 The association between sleep [29] disturbances and neuropsychiatric symptoms, cognitive and functional status of patients, and severity and duration of dementia

de Oliveira, 2014 [25] Factors related to sleep satisfaction in $\mathrm{AD}$ patients

No significant difference in functional impairment (ADL) for short sleep duration group versus $\geq 6 \mathrm{~h}$ TST; 39.1 versus 42.9 .

SDI scores were significantly associated with functional impairment (ADL) scores.

Greater functional impairment (ADL and IADL) for short sleep duration group versus $>6 \mathrm{~h}$ TST; 0.88 versus 2.60 and 1.9 versus 7.0, respectively.

Higher functional impairment (ADL) scores (less impairment) for sleep problems group versus no sleep problems; 3.5 versus 2.2 .

No significant difference in functional impairment (IADL) for sleep problems group versus no sleep problems; 7.6 versus 6.6.

Greater functioning (less functional impairment [IADL]) in those with higher \% sleep

Less daytime sleepiness (ESS) in those with higher \% sleep

Better QoL (QoL-AD) in those with higher \% sleep

Better physical QoL (SF-36) in those with higher \% sleep

Worse functioning (B-ADL), worse cognition (MMSE, RAVLT-IR, RAVLT-DR and TMT-B), depression (NPI) and aberrant motor behavior (NPI) were associated with sleep disturbances

No correlation between cognition (MMSE and clock drawing test) and sleep satisfaction.

No difference in functional impairment (ADL or IADL) for unsatisfied sleep group versus satisfied sleep (4.97 versus 5.02 and 15.32 versus 13.97, respectively).

Greater behavioral disturbances (NPI total score) and higher dysphoria, anxiety and apathy scores (NPI) in patients with unsatisfied sleep versus satisfied sleep. Significance for a decrease of $0.079 \mathrm{~h}$ of sleep for each point increase in anxiety score and for an increase of $0.075 \mathrm{~h}$ sleep for each point increase in apathy scores.

No association between functional impairment (ADL) and sleep duration.

Ribeiro, 2018 [61] Impact of sleep disorders, and manifestation in people with $\mathrm{AD}$

Yin, 2015 [70]

Five-year effect of nocturnal sleep disturbances on the long-term outcome in $\mathrm{AD}$ patients

Greater anxiety and depression (HADS) for sleep disturbances versus no sleep disturbances.

No significant differences in cognition (MMSE) or functional impairment (ADL) for sleep disturbances versus no sleep disturbances groups at baseline.

Significantly worse cognition (MMSE) and functional impairment (ADCS-ADL) for sleep disturbances group versus no sleep disturbances after five years.

Significant increase in cumulative incidence of psychotic symptoms, eating problems and sundowning syndrome for sleep disturbances group versus no sleep disturbances after five years. 
Table 2

(Continued)

\begin{tabular}{ll}
\hline Author & Relevant objectives assessed \\
\hline Leng, 2020 [44] & $\begin{array}{l}\text { Sleep quality and health-related QoL } \\
\text { in older adults with subjective } \\
\text { cognitive decline, mild cognitive } \\
\text { impairment, and AD }\end{array}$
\end{tabular}

Zhou, 2019 [71] Characteristics of sleep status and BPSD among AD patients in Eastern China, and the relationship among sleep disorder, behavioral and psychological symptoms of dementia, and cognition

Lebrija, 2016 [41] Sleep disorders and neuropsychiatric symptoms in Mexican patients with $\mathrm{AD}$

Clinical outcome results

Total (SF-36), physical (PHCS SF-36), and mental (MHCS SF-36)

QoL were associated with subjective sleep quality; moderate correlations between HRQoL and sleep quality. However, the AD group showed a weaker correlation than the other patient groups. Total and physical QoL were also moderately associated with sleep disturbances and total QoL alone was associated with sleep duration. Negative correlation between PSQI scores and cognition scores (MMSE) and functional impairment scores (ADCS-ADL).

PSQI was closely related to behavior/neuropsychological impairment scores (NPI total score) and depression and apathy scores (both NPI).

Significant association between anxiety (NPI) and difficulty falling asleep (versus patients without difficulty to initiate sleep), waking up at night (versus patients not waking up at night to start the day) and early morning awakenings (versus patients without early morning awakening).

Significant association between aberrant motor behavior (NPI) and waking up at night (versus patients not waking up at night), wandering at night (versus patients not wandering at night), night awakenings (versus patients without night awakenings) and early morning awakenings (versus patients without early morning awakening).

Significant association between agitation (NPI) and waking up at night to start the day (versus patients not waking up at night to start the day).

Kabeshita, 2017 [37] Sleep disturbances and other behavioral and psychological symptoms of dementia at different stages of $\mathrm{AD}$

Chew, 2019 [23] Sleep duration and progression of cognitive decline in subjects with mild cognitive impairment and mild AD

Escudero, 2019 [28] Association between neuropsychiatric symptoms and cognitive and functional decline in frontotemporal degeneration and $\mathrm{AD}$

Mulin, 2011 [55]

Apathy and sleep/wake patterns in individuals with $\mathrm{AD}$ using ambulatory actigraphy

Moran, 2005 [54] Sleep disturbance and its clinical correlates in a memory clinic population of $\mathrm{AD}$ patients

Leger, 2017 [43]

Impact of apathy or severity scores in patients with $\mathrm{AD}$ on TST at night

Behavior/neuropsychological impairment (NPI total score) was associated with sleep disturbances in patients with low CDR; no correlation in more severe $\mathrm{AD}$

Longer sleep duration in patients with rapid cognitive decline (CDR) versus those without

Sleep problems were predictive of cognitive decline after 2.5 years based on MoCA, but sleep problems at baseline were not associated with cognitive decline after 2.5 years based on MMSE.

The model on $\Delta$ Lawton (functional impairment - Lawton scale) reached significant values showing that variability in $\Delta$ Lawton was explained by the scores for depression and for sleep problems.

Greater WASO, time in bed, daytime inactivity periods and WASO normalized for time in bed in patients with apathy versus patients without apathy.

No significant difference in cognitive decline (MMSE, CAMCOG) and functional impairment (IADL, BDRS) between patients with and without sleep disturbances.

Significantly more aggressiveness (BEHAVE-AD) and worse behavioral disturbances (Global rating [BEHAVE-AD]) in patients with versus without sleep disturbances.

Negative correlation between TST and ADCS-ADL score, meaning TST was positively associated with functionally disability.

Increased TST (AES-I), decreased awakenings (AES-I), and increased sleep efficiency (AES-I) in patients with apathy versus patients without. 
Table 2

(Continued)

\begin{tabular}{lll}
\hline Author & Relevant objectives assessed & Clinical outcome results \\
\hline Shin, 2014 [63] & Impact of nighttime sleep on & No significant correlation between PSQI total scores and cognition \\
& (MMSE [Korean version]) or functional impairment (B-ADL, \\
psychological symptoms of & SI-ADL) in AD group. \\
& Apathy/indifference (NPI [Korean version]) significantly associated \\
& with PSQI total scores. \\
& Sleep latency was negatively associated between and visuospatial \\
& functions and praxis; sleep efficiency was positively associated with \\
& praxis, K-BNT and RCFT; sleep duration influenced praxis. \\
& After adjusting for age and education sleep latency was significantly \\
& associated with praxis, immediate recall and recognition, and sleep \\
& duration and efficiency correlated with praxis. \\
\hline
\end{tabular}

AD, Alzheimer's disease; ADCS-ADL, Alzheimer's Disease Cooperative Study-Activities of Daily Living; ADL, Activities of Daily Living; AES-I, Informant-rated Apathy Evaluation Scale; B-ADL, Bayer Activities of Daily Living; Ba-ADL, The Barthel Activities of Daily Living Index; BDRS, Blessed Dementia Rating Scale; BEHAVE-AD, Behavioral Pathology in Alzheimer's Disease; CAMCOG, Cambridge Examination for Mental Disorders of the Elderly; CDR, Clinical Dementia Rating; CSDD, Cornell Scale for Depression in Dementia; ESS, Epworth Sleepiness Scale; HADS, Hospital Anxiety and Depression Scale; IADL, Instrumental Activities of Daily Living; K-BNT, Korean version of the Boston Naming Test; MCI, mild cognitive impairment; MHCS, Mental Health Component Score; MMSE, Mini-Mental State Examination; MoCA, Montreal Cognitive Assessment; NPI, Neuropsychiatric Inventory; NR, not reported; PHCS, Physical Health Component Score; QoL, quality of life; QoL-AD, Quality of Life in Alzheimer's Disease; RAVLT-IR, Rey Auditory Verbal Learning Test; RCFT, Rey-Osterrieth Complex Figure Test; RMBPC, Revised Memory and Behavior Problems Checklist; SI-ADL, Seoul-Instrumental Activities of Daily Living Scale; SNSB, Seoul Neuropsychological Screening Battery; STAI Y-1, State Trait Anxiety Inventory for Adults; TMT-B, Trail-making test; TST, total sleep time; WASO, wake after sleep onset.

AD patients with and without sleep disturbances, but behavioral disturbances were significantly associated with sleep disturbance [54]. Two studies reported that longer sleep duration was associated with cognitive/functional impairment [23, 43]. In general, however, most studies have reported that poor sleep impacts both cognition and functional impairment.

Behavioral symptoms and neuropsychiatric functioning of $\mathrm{AD}$ patients are also worse among those with sleep disturbances, [25, 29, 41, 47, 54, 71] particularly depression and anxiety [25, 29, 58, 61, 71]. Several studies also reported significant associations between poor sleep and apathy in AD patients [55, 71]. Mulin et al. found that those with AD and apathy had reduced daytime activity levels and poorer nocturnal sleep quality [55]. Increased sleep and decreased circadian stability have also been associated with apathy in AD patients [25, 43]. Moran et al. found that sleep disturbances were associated with aggressiveness and greater global ratings for behavioral problems in AD patients [54]. Other studies reporting clinical impacts of sleep disturbances are summarized in Table 2.

Sleep problems are also associated with reduced QoL in AD patients [44, 47, 51]. Leng et al. reported that sleep disturbances, poor subjective sleep quality, and shorter sleep duration were all associated with reduced mental, physical or total QoL scores [44]. In line with this, greater actigraphically-defined sleep efficiency has been associated with better physical QoL scores in AD patients [51].

Longitudinal studies suggest that sleep disturbances in AD may predict worsening clinical symptoms. Yin et al. found significantly lower MMSE and Alzheimer's Disease Cooperative Study-Activities of Daily Living (ADCS-ADL) scores after five years in those reporting sleep disturbances, despite comparable scores in good versus poor sleepers at baseline [70]. They also reported a higher cumulative incidence of psychotic symptoms and sundowning syndrome among those with sleep disturbances after five years [70]. Escudero et al. also reported that sleep problems were predictive of cognitive and functional decline in AD patients (Montreal Cognitive Assessment [MoCA] [28].

\section{Caregiver burden and institutionalization of patients}

\section{Impact of insomnia/sleep disturbances on caregiver burden}

Caregiver burden associated with sleep problems in $\mathrm{AD}$ patients was overall found to be increased (20 of 21 studies; Table 3 ). Only one study reporting caregiver burden outcomes included patients with a sleep disturbance defined as insomnia (30.4\% with clinically diagnosed insomnia) [56]. Caregivers were typically spouses or adult children/grandchildren, 
Table 3

Studies reporting on the association between patient with $\mathrm{AD}$ and sleep disturbances and caregiver burden

\begin{tabular}{|c|c|c|c|c|c|}
\hline \multirow[t]{2}{*}{ Author } & \multirow[t]{2}{*}{ Study objective } & \multicolumn{3}{|c|}{ Caregiver characteristics } & \multirow[t]{2}{*}{ Clinical outcome result } \\
\hline & & Relationship to patient & Age (y) & Gender & \\
\hline Ownby, 2010 [57] & $\begin{array}{l}\text { Ethnic differences in sleep problems } \\
\text { among patients with } \mathrm{AD}\end{array}$ & $\begin{array}{l}\text { Spouse: } 44.05 \% \\
\text { Child/grandchild: } 48.39 \% \\
\text { Other relative: } 5.32 \% \\
\text { Other: } 2.02 \%\end{array}$ & NR & $\begin{array}{l}\text { F: } 105 \\
\text { M: } 286\end{array}$ & $\begin{array}{l}\text { Positive association (RC) between patients' difficulty falling } \\
\text { asleep, nighttime awakenings, and patient early morning } \\
\text { awakenings and caregiver depression (CES-D). }\end{array}$ \\
\hline Ownby, 2014 [58] & $\begin{array}{l}\text { Subtypes of sleep disturbance in } \\
\text { patients with } \mathrm{AD} \text {, and the relation } \\
\text { to patient characteristics and } \\
\text { caregiver mood }\end{array}$ & $\begin{array}{l}\text { Most frequently spouse or } \\
\text { adult child; study does } \\
\text { not report exact figures }\end{array}$ & $\begin{array}{l}\text { Mean (SD): } \\
\quad 57.3(14.9)\end{array}$ & $\begin{array}{l}\text { F: } 316 \\
\text { M: } 134\end{array}$ & $\begin{array}{l}\text { Higher caregiver depression (CES-D) scores for caregivers of the } \\
\text { moderate and severe sleep disturbances groups versus normal } \\
\text { sleep group. }\end{array}$ \\
\hline McCurry, 2004 [49] & $\begin{array}{l}\text { Anxiety and nighttime behavioral } \\
\text { disturbance in a } \\
\text { community-dwelling sample of } \\
\text { patients with AD }\end{array}$ & $\begin{array}{l}\text { Cohabiting with patient: } \\
94 \% \\
\text { See patient everyday: } 6 \% \\
\text { (female spouse: } 70 \% \text { ) }\end{array}$ & $\begin{array}{l}\text { Mean (SD): } \\
70.1(12.8)\end{array}$ & $\begin{array}{l}\text { Female } \\
\text { spouses: } \\
70 \%\end{array}$ & $\begin{array}{l}\text { Anxiety doubled the odds of awakening the caregiver at night } \\
\text { (caregiver reported) (OR 2.0,95\% CI: 1.4, 2.9). } \\
\text { Increased patient functional impairment in activities of daily life } \\
\text { was significantly related to awakening caregiver at night } \\
\text { (caregiver reported) (OR: } 1.6,95 \% \text { CI: } 1.2,2.3 \text { ). } \\
\text { No significant relationship between patient depression and } \\
\text { awakening caregiver at night (caregiver reported). }\end{array}$ \\
\hline McCurry, 2005 [50] & $\begin{array}{l}\text { Impact of comprehensive sleep } \\
\text { education program NITE-AD on } \\
\text { sleep in dementia patients living at } \\
\text { home with their family caregivers }\end{array}$ & Spouses: $58 \%$ & $21-87$ & F: $72 \%$ & $\begin{array}{l}92 \% \text { of caregivers of patients with sleep problems reported poor } \\
\text { sleep themselves (PSQI) (baseline). }\end{array}$ \\
\hline McCurry, 2006 [51] & $\begin{array}{l}\text { Caregivers' reports of sleep } \\
\text { disturbances in persons with } \mathrm{AD} \\
\text { and actigraphic records of patients' } \\
\text { sleep-wake activity, and } \\
\text { discrepancies in this relationship }\end{array}$ & $\begin{array}{l}\text { Spouses: } 54 \% \\
\text { Remaining were adult } \\
\text { relatives living with } \\
\text { patient }\end{array}$ & $21-87$ & $\begin{array}{l}\text { F: } 65 \% \\
\text { M: } 35 \%\end{array}$ & $\begin{array}{l}\text { Greater caregiver misperception of patient poor sleep associated } \\
\text { with higher caregiver burden (SCB) and more complaints of } \\
\text { caregiver poor sleep (PSQI, CSQ). }\end{array}$ \\
\hline McCurry, 1999 [47] & $\begin{array}{l}\text { Frequency, predictors, and impact of } \\
\text { sleep problems in a population- } \\
\text { based sample of } 205 \mathrm{AD} \text { patients }\end{array}$ & $\begin{array}{l}\text { Spouse: } 73 \% \\
\text { Adult child: } 6 \% \\
\text { Other: } 7 \% \\
\text { Lived away from patient } \\
\text { but saw them at least } \\
\text { weekly: } 14 \%\end{array}$ & $\begin{array}{l}\text { 32-94 } \\
\text { Mean: } 68\end{array}$ & F: $65 \%$ & $\begin{array}{l}\text { Positive correlation between increased frequency of all sleep } \\
\text { disturbances (except nightmares) and distress (RMBPC). } \\
70 \% \text { and } 69 \% \text { of caregivers reported 'awakening caregiver at night' } \\
\text { and 'patient sleeping less than usual' as moderately-severely } \\
\text { distressing (RMBPC), respectively. }\end{array}$ \\
\hline Gehrman, 2018 [31] & $\begin{array}{l}\text { Association between symptoms of } \\
\text { disturbed sleep in patients with AD } \\
\text { and caregiver burden outcomes. }\end{array}$ & $\begin{array}{l}\text { Spouse: } 81 \% \\
\text { Child: } 15 \% \\
\text { Other } 4 \%\end{array}$ & $\begin{array}{l}\text { Mean (SD) } \\
\quad 66.1(11.7)\end{array}$ & $\begin{array}{l}\text { F: } 61 \% \\
\text { M: } 39 \%\end{array}$ & $\begin{array}{l}\text { Significant associations between nocturnal awakenings, nocturnal } \\
\text { wanderings and daytime sleepiness compared with caregiver } \\
\text { burden (SCB) }\end{array}$ \\
\hline Lukovits, 1992 [45] & $\begin{array}{l}\text { To compare family members' and } \\
\text { nursing staff members' perceptions } \\
\text { regarding behavioral disturbances } \\
\text { in patients with severe AD }\end{array}$ & $\begin{array}{l}\text { Nurses and family } \\
\text { members }\end{array}$ & NR & NR & $\begin{array}{l}\text { Nurses reported more concern (5-point rating scale) than family for } \\
\text { vegetative behaviors (including sleep disturbances); concern } \\
\text { decreased with AD severity. }\end{array}$ \\
\hline
\end{tabular}


Table 3

(Continued)

\begin{tabular}{|c|c|c|c|c|c|}
\hline \multirow[t]{2}{*}{ Author } & \multirow[t]{2}{*}{ Study objective } & \multicolumn{3}{|c|}{ Caregiver characteristics } & \multirow[t]{2}{*}{ Clinical outcome result } \\
\hline & & Relationship to patient & Age (y) & Gender & \\
\hline Grace, 2000 [32] & $\begin{array}{l}\text { Frequency of sleep disturbances in } \\
\text { patients with AD and DLB and } \\
\text { impact on caregivers }\end{array}$ & NR & NR & NR & $\begin{array}{l}\text { Sleep disturbances were moderately-very severely distressing (NPI) } \\
\text { in } 8 / 20 \text { caregivers. }\end{array}$ \\
\hline Donaldson, 1998 [26] & $\begin{array}{l}\text { Impact of subgroups and individual } \\
\text { symptoms of non-cognitive } \\
\text { disturbance on the carers of AD } \\
\text { patients }\end{array}$ & $\begin{array}{l}\text { Lived with patient: } 74 \% \\
\text { Spouse: } 53 \% \\
\text { Child: } 36 \% \\
\text { Other relatives/ friends: } \\
\quad 11 \%\end{array}$ & $\begin{array}{l}\text { 32-87 Mean } \\
\text { (SD): } 63.1 \\
\text { (13.6) }\end{array}$ & F: $57 \%$ & $\begin{array}{l}\text { Positive correlations between sleep disturbances and caregiver } \\
\text { burden (GSS) and distress (GHQ); sleep disturbances predicted } \\
\text { distress in caregivers. }\end{array}$ \\
\hline de Oliveira 2014 [25] & Sleep satisfaction in patients with $\mathrm{AD}$ & NR & NR & NR & $\begin{array}{l}\text { No significant difference in caregiver burden (ZBI Brazilian } \\
\text { version) for unsatisfied sleep versus satisfied sleep. }\end{array}$ \\
\hline Camargos, 2015 [22] & $\begin{array}{l}\text { Trazodone on cognitive performance } \\
\text { in patients with } \mathrm{AD}\end{array}$ & NR & NR & NR & $\begin{array}{l}70.7 \% \text { of caregivers of patients with sleep disturbances reported } \\
\text { moderate/extreme distress (NPI); } 7.3 \% \text { reported mild distress. }\end{array}$ \\
\hline \multirow[t]{2}{*}{ Kazui, 2016 [38] } & $\begin{array}{l}\text { Differences of trajectories of } 12 \\
\text { kinds of BPSDs by disease severity } \\
\text { in four major dementias showing }\end{array}$ & NR & $\begin{array}{r}\text { Mean (SD) } \\
76.9(8.7)\end{array}$ & F: 752 & $\begin{array}{l}21.2 \%, 21.4 \%, 43.4 \% \text {, and } 76.5 \% \text { of caregivers of patients with } \\
\text { sleep disorders and CDR } 0.5 \text {, CDR } 1 \text {, CDR } 2 \text { and CDR3 had } \\
\text { moderate or greater distress (NPI-D), respectively. }\end{array}$ \\
\hline & $\begin{array}{l}\text { the frequency, severity, and } \\
\text { associated caregiver distress of } \\
\text { BPSDs using (J-BIRD) }\end{array}$ & & & M: 339 & $\begin{array}{l}\text { Significant differences between associated caregiver distress } \\
\text { (NPI-D) between CDR groups } 0.5-3 \text {. }\end{array}$ \\
\hline Okuda, 2019 [56] & $\begin{array}{l}\text { Sleep disturbance in AD patients and } \\
\text { the burden on, and health status of, } \\
\text { their caregivers in Japan }\end{array}$ & $\begin{array}{l}\text { Spouse: } 4.8 \% \\
\text { Child/grandchild } \\
\quad \text { (including } \\
\text { song/daughter-in law): } \\
88.7 \% \\
\text { Other: } 6.5 \%\end{array}$ & $\begin{array}{l}\text { Mean (SD): } \\
50.4(12.4)\end{array}$ & $\begin{array}{l}\text { F: } 50.2 \% \\
\text { M: } 49.8 \%\end{array}$ & $\begin{array}{l}\text { Significant positive correlation between patient sleep disturbances } \\
\text { and total care burden (BIC-11). } \\
\text { Significant positive association between patient sleep disturbances } \\
\text { and caregiver time-dependent emotional, existential, physical and } \\
\text { service-related, and total burden (BIC-11), caregiver depression } \\
\text { (Japanese PHQ-9) and caregiver poor sleep quality (Japanese } \\
\text { SF-12v2). } \\
\text { Significant negative association between patient sleep disturbances } \\
\text { and caregiver physical and mental QoL (Japanese SF-12v2). }\end{array}$ \\
\hline Allegri, 2006 [15] & $\begin{array}{l}\text { Predictive value of behavior-related } \\
\text { burden on AD caregivers }\end{array}$ & $\begin{array}{l}\text { Spouse: } 54.6 \% \\
\text { Child: } 36 \% \\
\text { Other: } 9.4 \%\end{array}$ & $\begin{array}{l}\text { Mean (SD): } \\
59.6(14.8)\end{array}$ & $\begin{array}{l}\text { F: } 67 \\
\text { M: } 15\end{array}$ & $\begin{array}{l}\text { Positive correlation between patient sleep disturbances and patient } \\
\text { abnormal behavior (wandering) compared with caregiver } \\
\text { burden/distress (ZBI). }\end{array}$ \\
\hline Yin, 2015 [70] & $\begin{array}{l}\text { 5-year effect of nocturnal sleep } \\
\text { disturbances on the long-term } \\
\text { outcome in AD patients }\end{array}$ & Spouse: $100 \%$ & NR & NR & $\begin{array}{l}\text { Increased caregiver negative emotions in group caring for patients } \\
\text { with sleep disturbances versus those caring for patients with no } \\
\text { sleep disturbances after } 5 \text { years. }\end{array}$ \\
\hline
\end{tabular}


Taemeeyapradit, 2014 Characteristics of the BPSD and its [67]

severity among patients with

dementia and their caregivers' stress

Pang, $2002[59]$

Cross-regional and cross-cultural differences in symptom-related caregiver distress due to behavioral problems of patients with $\mathrm{AD}$ symptoms in patients with a diagnosis of established AD for at least three years

Tractenberg 2003 [4] Efficacy of the SDI as an instrument for assessing symptoms of sleep disturbance/ disorder

Kim, 2017 [39] Impact of sleep disturbance in caregivers of $\mathrm{AD}$
NR

Spouse: $37.9-61.8 \%$ Child/sibling/child's spouse: $36.0-61.3 \%$ Friends/other: $0-15.5 \%$

US: 60 (14)

Taiwan: 59

(16)

Hong Kong: 58 (14)

Carer or next-of-kin

NR

20-39: $n=30$

$(18.99 \%)$

0-59: $n=109$

$(68.98 \%)$

$(12.02 \%)$

Live in caregivers

$47-92$

NR

NR (residing with patient)
F: $116 \quad$ Patient sleep disturbances rated in top four most burdensome (NPI

(73.42\%) Thai variant) symptoms (higher than irritability, depression, and anxiety).

M: $42 \quad 33.33 \%$ of caregivers of patients with sleep problems reported high $(26.58 \%) \quad$ suffering and were not capable of managing problem; $31.11 \%$ reported they were greatly troubled and patient sleep problems were difficult to manage; $20.00 \%$ reported considerable trouble and not easily managed.

F:M ratio: Patient sleep problems were moderately-very severely distressing (NPI) in $\sim 35 \%$ of caregivers from all ethnic groups (Taiwanese, Hong Kong Chinese and Caucasian American)

US: $1.7:$
Taiwan:

$2: 1$
Hong

Kong

$1: 1$

NR

Patient sleep disturbances were one of the least well tolerated BPSD (alongside aggression and irritability), causing high caregiver distress (NPI), despite medications*

F: 49\% Highest caregiver distress (NPI) for nighttime wandering and awakening caregiver.

Lower caregiver distress related to SDI items in patients with $\geq 6 \mathrm{~h}$ TST versus $<6 \mathrm{~h}$ TST.

Significant positive correlation between patient sleep problems and caregiver distress (NPI).

*High observed rates of drug use including cholinesterase inhibitors, antipsychotics, and antidepressants among patients. For studies using the NPI to assess caregiver distress, only the sleep disturbance item was considered for this review. AChEI,acetylcholinesterase inhibitor; AD, Alzheimer's disease; BIC-11, Burden Index of Caregivers-11; BPSD, behavioral and psychological symptoms of dementia; CDR, Clinical Dementia Rating; CES-D, Center for Epidemiological Studies Depression Scale; CSQ, Caregiver Sleep Questionnaire; DLB, Dementia with Lewy bodies; F, female; FTLD, frontotemporal lobar degeneration; GHQ, General Health Questionnaire; GSS, Gilleard's Strain Scale; HAMA, Hamilton Anxiety Scale; HDRS, Hamilton Depression Rating Scale; M, male; NITE-AD, Nighttime Insomnia Treatment and Education for Alzheimer's Disease; NPI, Neuropsychiatric Inventory; NR, not reported; n.s, not significant; PHQ-9, Patient Health Questionnaire-9; PSS, Perceived Stress Scale; PSQI, Pittsburgh Sleep Quality Index; QoL, quality of life; RC, regression model coefficient; RCT, randomized controlled trial; RMBPC, Revised Memory and Behavior Problem Checklist; SCB, Screen for Caregiver Burden; SD, standard deviation; SDI, Sleep Disorders Inventory; SF-12v2, 12-item Short Form Health Survey version; SF-36, 36-Item Short Form Health Survey; VaD, vascular dementia; ZBI,Zarit's Burden Interview. 
and frequently aged over 50 years, with a mean reported caregiver age of 60-80 years. Ownby et al. found sleep disturbances in $\mathrm{AD}$ patients were associated with greater caregiver depression, but cognitive decline was not controlled for in the study [58]. To this point, Kazui et al. reported a significant increase in sleep disturbance-associated distress among caregivers of patients with more severe AD [38]. The type of sleep problem is also a factor; McCurry et al. reported that nighttime awakenings, but not excessive sleeping, were most disturbing to caregivers and associated with greater memory impairment and worse functional status in patients [47].

The literature overwhelmingly suggested that sleep disturbances and disruptive nighttime behaviors (awakenings and wanderings) in AD patients are associated with considerable distress, poor health status and QoL, and reduced sleep in caregivers $[4,15$, $22,26,31,33,38,39,47,50,56,59,67]$. Interestingly, objective caregiver burden has also been associated with mis-perceived poor sleep quality in patients by caregivers [51]. Only one identified study reported that sleep disturbances were not associated with caregiver burden; de Oliveira et al. reported no significant difference between the burden in caregivers of patients with satisfactory versus unsatisfactory sleep [25].

Sleep disturbances in AD patients are also associated with caregiver depression, anxiety and mood, $[51,56-58,70]$ and have a negative impact on caregivers' overall QoL $[31,56]$. Caregivers' sleep worsened in the presence of patients' sleep disturbances; $[51,56]$. Okuda et al. found sleep disturbances in AD patients correlated significantly with higher caregiver PSQI scores (worse sleep quality) [56].

Several studies investigated the impact of specific sleep characteristics and behaviors on caregiver burden. Nighttime behaviors (awakenings and wanderings) had the largest impact on caregiver burden (four studies) [4, 15, 31, 47]. Notably, those with anxiety were twice as likely to waken their caregiver versus those without, and heightened anxiety was reported among patients taking sedative or hypnotic, antianxiety, antipsychotic or antidepressant medications, suggesting that the presence of anxiety led to the prescription of these medications [49].

\section{Institutionalization of AD patients with sleep disturbances}

Insomnia (two studies) [17, 18] and sleep disturbances (one study) [70] are key factors influencing the institutionalization of $\mathrm{AD}$ patients. In a five-year study, more AD patients with sleep disturbances (caregiver report of $\geq 2$ nighttime awakenings) lived in special dementia care units than those without sleep disturbances [70]. Baek et al. reported that a greater proportion of $\mathrm{AD}$ patients with insomnia were admitted to a long-term care facility and had longer durations of admission than those without insomnia [17]. Insomnia was also independently associated with admission to a nursing home after discharge from a dementia unit [18]. Importantly, other factors influence institutionalization, such as the availability of home services [18].

Thus insomnia/sleep disturbances may both accelerate the rate of deterioration of AD patients and lead to institutionalization. Interestingly, a 2006 study by McCurry et al. reported that misperception of patient sleep by caregivers in comparison to actigraphy was associated with greater objective caregiver burden [51]. Caregivers play a key role in the reporting and management of sleep disturbances in $\mathrm{AD}$ patients, and their perception of patients' sleep disturbance likely influences patient management, including the decision to admit $\mathrm{AD}$ patients into care facilities.

\section{Treatment of sleep disturbances in Alzheimer's disease}

Few insomnia treatment studies have been conducted in $\mathrm{AD}$ patients. We identified only 23 interventional studies and the majority were small (14 studies with $\leq 50$ subjects), highlighting the need for further studies to assess treatment efficacy and patient and caregiver outcomes in this population.

\section{Non-pharmacological treatments}

Of eight studies investigating non-pharmacological treatments, some found improvements not only in patients' sleep, but also other patient and caregiver outcomes (Table 4). Lee et al. reported improvement in subjective, but not objective, sleep (PSQI) in AD patients with insomnia treated with timed blue light, as well as improvements in behavioral disturbances and caregiver distress [42]. Ancoli-Israel et al. reported that daytime bright light exposure increased nocturnal sleep consolidation [16]. In contrast, some studies did not find light therapy effective in improving sleep overall [24, 27]. Of these studies, however, Dowling et al. found that people with the most impaired rest-activity rhythm responded to light therapy,[27] and van Someren et al.'s 1999 reanalysis of Colenda et al.'s 1997 study found that light therapy improved interdaily rhythm stability [24, 73]. 
Table 4

Impact of non-pharmacological treatments on sleep and clinical outcomes in AD patients

\begin{tabular}{lll}
\hline Author & Study objective & Intervention and comparator \\
\hline $\begin{array}{c}\text { Ancoli-Israel, } \\
2003[16]\end{array}$ & $\begin{array}{c}\text { Impact of light on sleep and } \\
\text { circadian activity rhythms in } \\
\text { patients with probable or }\end{array}$ & $\begin{array}{c}\text { Morning bright light }(2,500 \\
\text { lux }) \text { versus morning dim red }\end{array}$ \\
& $\begin{array}{l}\text { light }(<300 \text { lux }) \text { versus } \\
\text { possible AD }\end{array}$ & evening bright light $(2,500$ \\
& & lux $)($ average of 92.1 min \\
& treatment per 120 min \\
& session)
\end{tabular}
Clinical outcome result

Colenda, 1997

Dowling, 2005

Lee, 2018 [42]

McCurry, 2005

[50]

\section{Effects of phototherapy}

delivered by light visors on disturbed sleep patterns of community-dwelling research subjects with $\mathrm{AD}$
10 consecutive days of 2,000 lux of full spectrum bright light ( $2 \mathrm{~h}$ each morning)

No light treatment resulted in significant effects on actigraphically-measured sleep during night or day, using traditional sleep measures; TST, WASO, \% sleep, \% wake, number of nighttime awakenings, average length of nighttime awakenings, number of daytime naps, length of time between naps (wrist actigraphy).

Bouts of sleep at night (computed using actigraphy data) increased in the morning bright light group and evening bright light group at day 6-10; no significant change with dim light.

No significant difference in bouts of wake during the day (computed using actigraphy data) versus baseline for any group at day $6-10$. Mean wake-bout length decreased from day 6-10 to post-treatment follow up in the evening bright light group (rebound/relapse effect).

Activity rhythms (measured by wrist actigraphy) improved with evening bright light only for mean and maximum activity levels.

No significant changes in circadian rest-activity (actigraphy) at post-treatment versus baseline, except one subject. van Someren et al.'s 1999 reanalysis found that a nonparametric procedure indicated that light therapy improved interdaily rhythm stability [73].

Significant increase in TST (actigraphy) at post-treatment versus baseline for one subject and significant decrease for one subject.

No changes in nighttime awakenings (actigraphy) with treatment.

No significant changes in sleep efficacy, nighttime sleep time, nighttime wake time, number of nighttime awakenings, daytime wake time (all wrist actigraphy) with treatment versus control and no overall improvement in circadian rhythms (wrist actigraphy: parametric and nonparametric analysis) with treatment versus control; only subjects with the most impaired rest-activity rhythm responded to the light therapy.

Subjective sleep (PSQI) scores significantly decreased with treatment/ no significant changes in objective sleep with treatment versus baseline.

Patient's neuropsychiatric symptoms (NPI-S) and caregiver distress (NPI-D) scores reduced after treatment; not significant.

Improvement in time awake at night (wrist actigraphy) from baseline with treatment; maintained over 6-month follow up.

Fewer nighttime awakenings (wrist actigraphy) with treatment versus control $(32 \%$ reduction from baseline).

Significantly lower levels of depression (RMBPC) with treatment versus control, maintained over 6-month follow up.

Lower daytime sleepiness (ESS) with treatment versus control over 6-month follow up (controlling for MMSE). 
Table 4

(Continued)

\begin{tabular}{|c|c|c|c|}
\hline Author & Study objective & Intervention and comparator & Clinical outcome result \\
\hline $\begin{array}{l}\text { McCurry, 2011* } \\
{[52]}\end{array}$ & $\begin{array}{l}\text { Effects of walking, light } \\
\text { exposure, and a combination } \\
\text { intervention (walking plus } \\
\text { light plus sleep education) on } \\
\text { the sleep of persons with AD }\end{array}$ & $\begin{array}{l}\text { NITE-AD versus walking } \\
\text { versus light therapy }(\sim 2500 \\
\text { lux }) \text { versus control }\end{array}$ & $\begin{array}{l}\text { Reduced total wake time at night (wrist } \\
\text { actigraphy) for walking, light and NITE-AD } \\
\text { with treatment versus control. No difference } \\
\text { between active treatment groups. Improvements } \\
\text { not maintained over time in 6-month } \\
\text { longitudinal analysis. } \\
\text { Trend for fewer awakenings (wrist actigraphy) for } \\
\text { the walking group versus control. } \\
\text { Moderate effect size improvements in sleep } \\
\text { percent (wrist actigraphy) for active treatment } \\
\text { groups. } \\
\text { No significant difference in TST (wrist actigraphy) } \\
\text { and caregiver-reported patient sleep (SDI) } \\
\text { between groups. }\end{array}$ \\
\hline $\begin{array}{l}\text { McCurry, } 2003 \\
\text { [48] }\end{array}$ & $\begin{array}{l}\text { Feasibility of training } \\
\text { caregivers to implement sleep } \\
\text { hygiene recommendations in } \\
\text { dementia patients }\end{array}$ & $\begin{array}{l}\text { Caregivers received training } \\
\text { and tailored } \\
\text { recommendations/education } \\
\text { to aid their implementation of } \\
\text { sleep hygiene strategies } \\
\text { among patients versus } \\
\text { nondirective support }\end{array}$ & $\begin{array}{l}\text { Patients adhered to sleep hygiene goals (consistent } \\
\text { bedtime, consistent rising time, nap restriction, } \\
\text { walking) significantly more consistently in } \\
\text { active training group. Changes in sleep hygiene } \\
\text { behaviors occurred more often if caregivers } \\
\text { received specific suggestions/assistance }\end{array}$ \\
\hline $\begin{array}{l}\text { Simoncini, } 2015 \\
{[64]}\end{array}$ & $\begin{array}{l}\text { Effectiveness of acupressure for } \\
\text { the treatment of insomnia and } \\
\text { other sleep disturbances, and } \\
\text { to show that the acupressure } \\
\text { treatment is feasible also in } \\
\text { elderly resident patients }\end{array}$ & Daily acupressure for 8 weeks & $\begin{array}{l}\text { Positive subjective perception of sleep after } \\
\text { treatment and maintained at follow up; hours of } \\
\text { sleep perceived to be increased; time to fall } \\
\text { asleep decreased; quality of sleep increased. } \\
\text { Significant improvement in general health } \\
\text { (GHQ28) with treatment versus baseline: PSQI } \\
\text { significantly correlated to GHQ28 with good } \\
\text { sleep encouraging perception of better health. } \\
\text { Positive difference found with regard to sleep } \\
\text { and mood. } \\
\text { No change in cognitive functioning (MMSE) and } \\
\text { functional status (ADL, IADL) with treatment } \\
\text { versus baseline. } \\
\text { Improvement in behavioral and psychological } \\
\text { functioning (NPI) and positive non-significant } \\
\text { trend of improvement in anxiety (STAI Y-1) } \\
\text { after treatment. }\end{array}$ \\
\hline
\end{tabular}

*Post-test outcomes controlled for baseline age, gender, depression, comorbidity limitations, MMSE and sleep apnea scores. ADL, Activities of Daily Living; ESS, Epworth Sleepiness Scale; GDS, Global Deterioration Scale; GHQ28, Global Health Quality of Life; IADL, Instrumental Activities of Daily Living; MMSE, Mini-Mental State Examination; NITE-AD, Nighttime Insomnia Treatment and Education for Alzheimer's Disease; NPI, Neuropsychiatric inventory; PSQI, Pittsburgh Sleep Quality Index; STAI Y-1, State Trait-Anxiety Inventory; TST, total sleep time: WASO, wake after sleep onset.

Acupressure treatment was assessed in one study and improved sleep in elderly institutionalized AD patients with insomnia, but had no effect on cognition (MMSE) or functional status (ADL) [64].

McCurry et al. reported that an approach combining sleep hygiene, walking, and light exposure (NITE-AD) reduced the frequency and duration of nighttime awakenings, and lowered daytime sleepiness (Epworth Sleepiness Scale [ESS]) and levels of patient depression (RMBPC) versus controls [50]. They also reported improvements in patients' actigraphically-measured total wake time with NITE$\mathrm{AD}$ versus controls; similar results were reported for the groups receiving light and walking therapies [52]. However, caregiver-reported subjective outcome measures (Sleep Disorders Inventory [SDI]) did not replicate these results, but caregiver reports are not always consistent with actigraphy [52]. Unfortunately, improvements in sleep with any interventions were not sustained at six months, likely due to reduced adherence over time [52]. Indeed, in the latter NITE-AD study, patients adhering to recommendations $\geq 4$ days/week had significantly better sleep outcomes [52]. These findings highlight a key challenge with non-pharmacological treatment, which may not always be feasible in patients with $\mathrm{AD}$ and 
other comorbidities due to inability or lack of willingness to partake. Notably, active training and support for caregivers led to a greater success in implementing good sleep hygiene practices in AD patients [48].

\section{Pharmacological treatments}

Only 15 studies investigated the effects of pharmacological sleep treatments in AD patients (Table 5). Although several treatments showed promise in improving clinical and caregiver symptoms, inconsistent clinical results were also apparent and there are insufficient data supporting many commonly used treatments.

\section{Benzodiazepines and non-benzodiazepine ' $z$-drugs'} A small study $(N=7)$ by McCarten et al. investigated the efficacy of the benzodiazepine triazolam ( $0.125 \mathrm{mg}$ at bedtime) in patients with AD but failed to detect significant effects on sleep parameters versus placebo (Table 5) [46]. Yin et al. reported improvements in sleep quality (PSQI) and daytime sleepiness (ESS) with the non-benzodiazepine zolpidem tartrate, versus no treatment in a 5-year study; no change was seen in MMSE, ADCS-ADL or NPI scores with zolpidem tartrate after five years versus no treatment, suggesting no significant impact on cognitive decline or neuropsychiatric behaviors, but no safety outcomes were reported [70].

Melatonin/melatonin receptor agonists Two studies found melatonin to be ineffective at improving sleep, agitation scores, or circadian rhythm parameters in $\mathrm{AD}$ patients based on actigraphy [30, 65]. Conversely, Brusco et al., reported significant improvement in sleep quality and decreased sundowning with melatonin $9 \mathrm{mg}$, but this was an open label study with only 14 patients [20]. Similarly, Wade et al. reported significantly improved sleep efficiency among AD patients with insomnia taking prolonged-release melatonin in a doubleblind, placebo-controlled study after 24 weeks, but PSQI scores were not significantly different between groups [69]. Cognition was also improved with melatonin versus placebo (for MMSE and AD Assessment Scale-Cognition scores), as well as self-care and activities of daily living scores (IADL) [69].

Antidepressants A small study by Camargos et al. found that trazodone $50 \mathrm{mg}$ increased sleep duration and efficiency in AD patients versus placebo, was well-tolerated, and did not increase daytime sleepiness [21]. Petrescu et al. also reported that patients taking trazodone (50-200 mg) had more total sleep time in both patient- and nurse-reported measures, although it was associated with more side effects than quetiapine [60]. Interestingly, trazodone may have a possible neuroprotective effect in $\mathrm{AD}$ patients with insomnia; a retrospective study by $\mathrm{La}$ et al. reported that among a group of older adults, including some with $\mathrm{AD}$, those not using trazodone declined 2.4-fold faster than trazodone users (median dose $50 \mathrm{mg}$ ) across an average of 3.75 years based on MMSE results [40]. Notably, while trazodone is an antidepressant, a dose of $50 \mathrm{mg}$ is consistent with use for insomnia, rather than depressive disorders. A small study assessing the antidepressant mirtazapine reported no effects on sleep outcomes in $\mathrm{AD}$ patients (Table 5) [62].

Antipsychotics A five-year study by Yin et al. reported improved daytime (ESS) and nighttime (PSQI) sleep symptoms with low-dose risperidone versus zolpidem tartrate, melatonin, or no drug treatment in $\mathrm{AD}$ patients with sleep disturbances [70]. Risperidone also alleviated neuropsychiatric symptoms (NPI) versus no treatment and did not significantly affect cognition or functional autonomy versus zolpidem, melatonin, or no treatment, suggesting no acceleration in mental deterioration [70]. Risperidone was also associated with a significant improvement in caregiver mood and sleep and a lower expectation that a patient would be institutionalized versus the melatonin and no treatment groups, implying improved outlook; institutionalization of risperidone-treated patients was significantly lower than in patients not receiving sleep medication [70]. However, this was not a randomized trial, and treatment group assignment was based on the preference of the spousal caregiver. In a nursing home-based study, Meguro et al. reported that low-dose risperidone was effective at increasing patient sleep and decreasing daytime wandering [53]. Importantly, patients did not exhibit daytime oversleeping or side effects which would have prevented them participating in daily activities [53].

Orexin receptor antagonists Orexin receptor antagonists have emerged as a new generation of insomnia treatments. In a polysomnography study of $\mathrm{AD}$ patients with insomnia, Herring et al. reported that suvorexant significantly increased total sleep time versus placebo, and decreased waking after sleep 
Table 5

Pharmacological treatments: impact on sleep and clinical outcomes in AD patients

\begin{tabular}{lll}
\hline Author & Study objective & Intervention and comparato \\
\hline $\begin{array}{c}\text { Brusco, 1999 } \\
{[20]}\end{array}$ & $\begin{array}{l}\text { Melatonin in selected } \\
\text { populations of } \\
\text { sleep-disturbed patients }\end{array}$ & $\begin{array}{c}\text { Melatonin } 9 \mathrm{mg}, \text { for 22 to 35 } \\
\text { months }\end{array}$ \\
\end{tabular}

Camargos, 2014 Trazodone to treat sleep disturbances in patients with $\mathrm{AD}$

Gehrman, 2009 [30]

Hannesdottir, 2013 [34]

Herring, 2020

Ishikawa, 2016

[36]
Melatonin effects on sleep and agitation in institutionalized

AZD5213 effects on sleep in subjects with mild cognitive impairment and mild AD

Suvorexant for treating insomnia in patients with $\mathrm{AD}$ using sleep laboratory polysomnography experiments

\section{Memantine on}

polysomnography variables and behavioral and psychological symptoms of dementia patients with $\mathrm{AD}$
Trazodone $50 \mathrm{mg}$ versus placebo for two weeks

Melatonin $8.5 \mathrm{mg}$ immediate-release and $1.5 \mathrm{mg}$ sustained release combined dose (nightly) versus placebo for 10 days

Anti-histamine AZD5213 (three different doses) versus placebo for four weeks

Suvorexant $10 \mathrm{mg}$ (increased to $20 \mathrm{mg}$ based on clinical response) versus placebo four weeks

Memantine $5 \mathrm{mg}$, increased by $5 \mathrm{mg}$ each week up to $20 \mathrm{mg}$ for four weeks

Clinical outcome result

Sleep quality (clinical interviews and sleep logs; caregiver-reported) improved and sundowning measure was no longer detected in 12/14 patients from baseline with melatonin. No differences in the evolution of disease with melatonin versus baseline based on neuropsychological/cognitive functioning tests (FAST; MMSE)

Nighttime total sleep time (actigraphy) increased by 8.5 percentage points post-treatment with trazodone; $42.5 \mathrm{~min}$ more of sleep with trazodone versus placebo.

Daytime sleepiness and naps (actigraphy) not induced in either group.

Trended towards reduction in time spent awake after sleep onset and number of awakenings (actigraphy) with trazodone; not significantly different between group.

No effect on cognitive functioning (MMSE) with either treatment

No significant treatment effects on sleep (TST night, \% sleep in night, WASO, $\%$ wake, total daytime sleep, $\%$ sleep in day, number and mean duration of sleep episodes) and circadian rhythm parameters (actigraphy) with melatonin versus placebo, and no change from treatment to follow up.

Dose-related increase in sleep-related AEs with two higher doses of AZD5213/ TST (PSG) reduced with two higher doses of AZD5213 versus placebo (no change with low dose).

Decrease in TST did not result in impairment in next-day functioning (Psychomotor Vigilance Task and subjective reports of daytime sleepiness).

Only small and non-clinically relevant effects on attention/response speed and memory accuracy (CogState tasks) with AZD5213.

Greater LS mean change (improvement) from baseline in TST (PSG), greater proportion of patients with $\geq 50 \mathrm{~min}$ improvement in TST and greater LS mean change from baseline in WASO (PSG) at week 4 with suvorexant versus placebo. No differences between groups on objective cognitive (MMSE) and psychomotor tests (digit substitution), or trial partner-reported neuropsychiatric symptoms (NPI).

At week 4, memantine was associated with improved mean subjective sleep scores (AIS) and significant improvements in neuropsychological functioning and behaviors (NPI total score), TST (PSG), sleep efficiency (PSG), and nighttime awakenings (PSG) versus baseline.

At week 4, memantine was associated with a significant decrease in anxiety (NPI) and irritability (NPI) versus baseline but did not result in a significant difference in cognitive functioning (MMSE) or dementia rating (CDR). 
Table 5

(Continued)

\begin{tabular}{ll}
\hline Author & Study objective \\
\hline La, 2019 [40] & $\begin{array}{l}\text { Long-term use of trazodone } \\
\text { and delayed cognitive decline }\end{array}$ \\
$\begin{array}{ll}\text { McCarten, 1995 } & \begin{array}{l}\text { Triazolam, in patients of AD } \\
\text { who were reported by } \\
\text { caregivers to be frequently up } \\
\text { at night }\end{array}\end{array}$
\end{tabular}

Meguro, 2004

[53]

Petrescu, 2019

[60]

Scoralick, 2017 Mirtazapine in the treatment of [62] sleep disorders in patients with $\mathrm{AD}$
Risperidone in treating wandering and disturbed sleep/wake patterns in patients of $\mathrm{AD}$ among inpatients clinically stable psychiatric
Risperidone $1 \mathrm{mg} /$ day versus non-risperidone for one month
Intervention and comparator Trazodone (median prescribed dose: $50 \mathrm{mg}$ ) versus matched non-trazodone users (over two consecutive annual visits)

Triazolam $0.125 \mathrm{mg}$ (two nights); patients acted as own control, receiving placebo for three nights prior- and two nights post-treatment
Clinical outcome result

Non-users' cognitive functioning (MMSE) declined 2.4-fold faster than trazodone users' across an average of 3.75 years.

No significant effects on TST at night, latency to sleep onset, number of nighttime awakenings, TST in the day, mean level of activity in night or day (actigraphy) with triazolam.

$3 / 6$ with full data showed modest hypnotic response with increases in TST, but more nocturnal arousals with triazolam.

Withdrawal effect reported in 3/7 patients during placebo wash-out (decreased TST at night)

No significant drug versus placebo effects on memory (computerized memory test), and no relationship with patients' response to treatment.

Daytime sleeping hours (caregiver-rated) decreased by $1.2 \mathrm{~h}$, nighttime sleep hours (caregiver-rated) increased by $3.8 \mathrm{~h}$ and wandering hours (caregiver-rated) decreased by $2.7 \mathrm{~h}$ with risperidone versus pre-treatment. Post $h o c$ analysis found significant difference in nighttime sleep hours between pre- and post-treatment with risperidone.

No new daytime oversleeping or side effects that would have prevented participation in daily activities (caregiver-rated) with risperidone.

No deterioration in cognitive functioning (MMSE and CASI) following risperidone treatment; some improvement shown for some patients (CASI).

Trazodone 50-200 mg versus quetiapine $50-300 \mathrm{mg}$ (treatment period: NR)

Mirtazapine $15 \mathrm{mg}$ versus placebo for 14 days

Longer TST (patient' subjective reports, nursing sleep logs) and daily dizziness (patients' subjective report) reported in patients taking trazodone versus quetiapine.

Sleep efficiency (nursing sleep logs) similar between groups.

No significant effects on nighttime TST (actigraphy) with mirtazapine versus placebo (gain of 55.3 min versus placebo).

No significant decrease in WASO (actigraphy) nighttime awakenings, and \% sleep with mirtazapine versus placebo.

No effect on cognitive function (MMSE) or functional status (Katz scale) with mirtazapine versus placebo.

Significant effect on daytime sleep duration with mirtazapine versus placebo, but no impact on naps.

Weak non-significant trend for more TST at night (actigraphy) in the melatonin groups versus placebo.

Very weak trend for decreased day-night sleep ratio (actigraphy) and significantly greater sleep quality (caregiver-reported sleep logs) for the melatonin $2.5 \mathrm{mg}$ group versus placebo.

Changes in neuropsychological symptoms and behaviors (NPI) only seen in melatonin $2.5 \mathrm{mg}$ group versus placebo; this was due to baseline differences and changes were not associated with changes to sleep.

No significant difference in sleep-related symptoms (SDI) between groups. 
Table 5

(Continued)

\begin{tabular}{lll}
\hline Author & Study objective & Intervention and comparato \\
\hline Stahl, 2004 [66] & $\begin{array}{c}\text { Galantamine, and night time } \\
\text { sleep related problems }\end{array}$ & $\begin{array}{c}\text { Galantamine } 8 \mathrm{mg} \text { bid vers } \\
\text { galantamine } 12 \mathrm{mg} \text { bid ve } \\
\text { placebo (data from three } \\
\text { trials; treatment period: }\end{array}$ \\
Wade, 2014 [69] & $\begin{array}{l}\text { Melatonin on cognitive } \\
\text { function and sleep in patients } \\
\text { with mild to moderate AD }\end{array}$ & $\begin{array}{l}\text { Melatonin 2 mg } \\
\text { prolonged-releaseversus } \\
\text { placebo for 24 weeks }\end{array}$
\end{tabular}

Yin, 2015 [70]

5-year effect of nocturnal sleep disturbances on the long-term outcome in AD patients
Risperidone $0.5-1 \mathrm{mg}$ versus zolpidem tartrate $5-10 \mathrm{mg}$ versus melatonin $2.55 \mathrm{mg}$ versus no drug over five years
Clinical outcome result

Sleep-related AEs (physician-reported) not significantly different between groups.

Significantly more overall concomitant sleep medication use in galantamine $24 \mathrm{mg}$ group versus galantamine $16 \mathrm{mg}$ group; no other significant differences in pairwise comparisons.

Sleep efficiency (PSQI completed by investigator with the caregiver or patient; caregiver report prioritized), cognitive functioning (ADAS-Cog, MMSE), and functional status (IADL) improved significantly with melatonin versus placebo at 24 weeks.

No difference in PSQI global scores (completed by investigator) between groups at 24 weeks. Trend for improvement in sleep quality (sleep diary) with melatonin at week 12 .

No differences in neuropsychological symptoms and behaviors (NPI) between groups. Decreased caregiver distress (SDI) in both groups.

Significantly lower institutionalization to special dementia care units and incidence of psychotic symptoms with risperidone versus no drug after 5 years.

No significant differences in cumulative incidences of syndrome, cognitive functioning (MMSE), functional impairment (ADCS-ADL) and incidences of eating problems between groups after 5 years.

Significantly lower psychiatric symptoms (NPI) with risperidone versus placebo.

Significantly lower daytime sleepiness (ESS), significantly increased sleep quality (PSQI), caregiver depression (HAMD), less pronounced increase in caregiver anxiety (HAMA), improved caregiver sleep quality (PSQI), less caregiver daytime sleepiness (ESS) with risperidone versus other groups after 5 years; significantly lower with zolpidem tartrate versus no drug after 5 years.

Significantly lower caregiver increased hope that patient would be admitted to a nursing home with risperidone versus melatonin and no drug after 5 years; no difference versus zolpidem tartrate

(Caregiver emotional attitude assessed via self-made questionnaire).

AD, Alzheimer's disease; ADCS-ADL, Alzheimer's Disease Cooperative Study-Activities of Daily Living; ADAS-Cog, Alzheimer's Disease Assessment Scale - Cognition; AE, adverse event; AIS, Athens Insomnia Scale; bid: twice a day; CASI, Cognitive Abilities Screening Instrument; CDR, Clinical Dementia Rating; CGI, Clinical Global Impression; ESS, Epworth Sleepiness Scale; FAST, Functional Assessment Tool for AD; HAMA, Hamilton Anxiety Scale; HAMD, Hamilton Depressive Scale; LS, least squares; MMSE, Mini-Mental State Examination; NPI, Neuropsychiatric Inventory; NR, not reported; PSG, polysomnography; PSQI, Pittsburgh Sleep Quality Index; TST, total sleep time; WASO, wake after sleep onset.

onset, with no worsening of cognitive (MMSE) or psychomotor tests (digit symbol) [35]. Currently, suvorexant is the only pharmacotherapy specifically approved for the treatment of insomnia in AD patients, although other drugs in this class are also being tested in the $\mathrm{AD}$ population.

\section{DISCUSSION AND CONCLUSION}

This literature review demonstrates that sleep disturbances in $\mathrm{AD}$ patients are associated with greater cognitive decline, poorer functional ability and reduced QoL. Furthermore, behavioral symptoms 
and neuropsychiatric functioning of $\mathrm{AD}$ patients, including depression, apathy, psychotic symptoms, and sundowning syndrome, are more frequent and severe among those with sleep disturbances. Sleep disturbances and associated disruptive nocturnal behaviors in $\mathrm{AD}$ patients also result in considerable caregiver burden, including increased distress, depression and sleep problems, and decreased QoL. Sleep disturbances are a major factor influencing the institutionalization of AD patients, likely through their impact on caregiver burden. Previous reviews have also identified nighttime awakenings and troublesome behaviors (e.g. wandering) as the most burdensome symptoms and key motivating factors for institutionalization $[1,74]$.

In addition, sleep problems have been associated with increased risk for development and progression of $\mathrm{AD}[9,11,28,70]$. Recent meta-analyses found that patients with insomnia had a 1.51-fold higher risk (95\% CI: 1.06-2.14) of developing $\mathrm{AD},[11]$ and that patients with sleep problems had a $1.55(95 \%$ CI: 1.25-1.93) times higher risk of $\mathrm{AD}$ and a 1.65 (95\% CI: 1.45-1.86) and 3.78 (95\% CI: 2.27-6.30) times higher risk of cognitive impairment and preclinical AD, than people with no sleep problems, respectively [9].

However, evidence of the independent association of sleep problems and clinical outcomes is generally lacking in the literature. Caregiver burden is likely to be multifactorial and impacted by variables beyond patients' sleep symptoms, including the severity of patients' AD. Multiple patient and caregiver factors influence the institutionalization of AD patients, not only the overall clinical status of AD patients, but also the health, functionality, and economic status of their caregivers.

Nevertheless, insomnia and other sleep disturbances are recognized factors contributing to increased burden in AD patients, and the effective management and treatment of sleep symptoms may be helpful in improving clinical outcomes and delaying institutionalization. However, sleep problems are not only poorly characterized in this population, but there are also very few studies evaluating the effects of sleep treatments specifically in AD patients. Nonpharmacological sleep treatments, such as behavioral and light therapy, are typically used as first-line approaches in patients with insomnia and sleep disturbances, despite a lack of consistent data and standardized recommendations in this population $[1,75]$. However, access to non-pharmacological sleep treatments is limited due to availability and cost restraints [5]. The limited research for nonpharmalogical sleep treatments reflects the obstacles faced with initiating practices in clinical care, particularly in low-resource environments, such as the cost, time taken to train carers, limited equipment, and lack of clear guidelines to deliver treatment [76]. For patients with dementia and in long term care, patients may also be unable or unwilling to partake in such therapies, preventing successful implementation [5]. Implementing approaches that actively include input from care staff, residents and their families may help overcome the challenges asscoiated with non-pharmacological treatments in long-term care [76]. Practices that aim to improve the daily routines and quality of the sleeping enviroment for AD patients in care homes (such as the LOCK program, a specific frontline staff huddling program which enables staff to: Learn from bright spots; Observe; Collaborate in huddles; and Keep it bite-size) may also help alleviate sleep disturbances in this population [77]. Importantly, strategies that include interventions in several behavioral and environmental domains, such as sleep hygiene, light exposure and exercise, have shown some promise, which may suggest that a combined approach to behavioral therapy could improve outcomes [50]. Implementation of non-pharmacological treatments may reduce the likelihood of patient institutionalization and the associated economic burden, but successful implementation remains a key challenge in $\mathrm{AD}$ patients. Furthermore, many patients may require pharmacotherapies alongside these strategies to ensure patients can be treated at home for as long as possible.

Many currently available pharmacological treatments for insomnia are associated with a risk of further cognitive impairment, falls and fractures, and next-day residual effects in the elderly and therefore should be carefully evaluated prior to being prescribed. Studies investigating insomnia therapies in elderly patients have largely excluded patients with cognitive impairment or dementia. As a result, there remains uncertainty about the balance of benefits and risks associated with common sleep treatments when used in $\mathrm{AD}$ [78].

Few studies evaluating the use of sleep medications in $\mathrm{AD}$ patients were identified and were generally small. While treatments such as trazodone, [21, 40, 60] risperidone[53, 70] and suvorexant [35] showed some promise in improving clinical and caregiver symptoms, further data from larger, prospective trials are required. Previous reviews have drawn similar 
conclusions, highlighting the scarcity and contradictory nature of current evidence $[1,79]$.

Benzodiazepines are also frequently used in $\mathrm{AD}$ patients, [79, 80] but a systematic literature review by Defrancesco et al. (2015) reported no conclusive evidence for the improvements in sleep quality in AD patients taking benzodiazepines [81]. Moreover, benzodiazepines are associated with side effects including daytime sleepiness, worsened insomnia, confusion and amnesia. Though non-benzodiazepine 'z-drugs' may be associated with fewer side effects than benzodiazepines, [1, 10, 82] adverse events are still apparent. The American Geriatric Society recommends that both benzodiazepines and nonbenzodiazepines be avoided in the elderly [14].

This review found mixed results between studies evaluating melatonin, which echoes findings from previous reviews [80, 83, 84]. A 2016 Cochrane review concluded that melatonin was unlikely to benefit AD patients with sleep problems [85]. Conversely, the combination of melatonin and brightlight therapy has been shown to have beneficial results in the nocturnal sleep of AD patients, $[1,10]$ suggesting a multifaceted approach targeting circadian rhythm stabilization may enhance the outcomes of sleep treatments in $\mathrm{AD}$, which is not surprising given that $\mathrm{AD}$ patients tend to have both sleep and circadian rhythm disturbances.

The use of antipsychotics in the treatment of sleep and other behavioral disturbances in $\mathrm{AD}$ has been extensively discussed [1, 10, 82, 86, 87]. While they may be useful in the treatment of sleep disturbances and to alleviate neuropsychiatric symptoms, [70] they are not without risks. While no significant adverse events were reported in the studies included in this review, antipsychotics can cause residual sedation, confusion and falls, and have metabolic and cardiovascular side effects $[1,10,86,88,89]$. Antipsychotics also carry a black-box warning from the FDA for increased death in the elderly with dementia.

Suvorexant, currently the only approved pharmacotherapy for insomnia in $\mathrm{AD}$, has demonstrated improved sleep and was well-tolerated in AD patients [35]. Suvorexant has also been shown to improve sleep maintenance and onset and was well-tolerated in elderly patients with insomnia [90]. Lemborexant, another orexin receptor antagonist, has also demonstrated promising results in improving sleep without significant adverse events in elderly patients [91]. Although not the focal population for this review, lemborexant has shown beneficial results in nighttime and daytime symptoms with no worsening in cognitive functioning in AD patients with Irregular Sleep-Wake Rhythm Disorder (ISWRD) [92]. However, at present, the suvorexant trials in elderly patients and those with $\mathrm{AD}$ have reported far more conclusive results, based on objective PSG measures $[35,90]$. While orexin receptor antagonists have been highlighted as promising options for elderly patients and those with dementia across the literature, data so far are limited [1, 79, 93].

The paucity of studies evaluating therapies in this population highlights the importance of further research in people with or at risk for $\mathrm{AD}$, as there is insufficient evidence that treatments suitable for non-demented elderly persons will have an advantageous benefit-to-risk ratio in AD patients [14, 93]. Importantly many current studies do not adequately categorize sleep problems in AD patients which may include insomnia and circadian rhythm disorders. Successful treatment likely requires addressing both disorders which may have impacted the results in studies assessing the treatment of insomnia alone. As studies reporting data for sleep disorders other than insomnia, such as obstructive sleep apnea, were excluded from this analysis, this review has not discussed the burden of sleep disorders existing comorbidly with insomnia in AD patients. However, as the presence of comorbid sleep disorders may influence the clinical presentation and burden of symptoms, the impact of available sleep treatments in these patients should be further considered.

\section{Limitations}

There are several limitations to this review, with the most significant being that publications reported on sleep disturbances and insomnia without clear and consistent definitions. Sleep in AD is characterized by increased insomnia and sleep fragmentation, as well as circadian rhythm abnormalities, including deterioration and instability of rhythms, with delayed sleep phase and daytime napping. AD patients also have an increased rate of other sleep disorders that further contribute to sleep disturbance, including sleep apnea, sleep movement disorders (e.g., restless legs), and parasomnias such as REM sleep behavior disorder [94-97]. Furthermore, medications commonly given to $\mathrm{AD}$ patients including many antidepressants, cholinesterase inhibitors, and memantine can cause or worsen insomnia. In general, the studies covered in this review did not comprehensively assess and enumerate the specific sleep and rhythm disturbances 
in participants, evaluate them for other sleep disorders, or control for medication effects. As a result, it is likely that sleep problems and sleep disorders other than insomnia were captured, particularly in studies that used non-specific definitions for sleep disturbance. For example, the NPI question used to assess sleep disturbance in many of the studies simply asks, "Does the patient awaken you during the night, rise too early in the morning, or take excessive naps during the day?"; it combines symptoms of insomnia with excessive sleepiness, and the questionnaire does not include screening for other sleep disorders.

Studies in this review generally did not control for other factors that could have influenced the clinical burden of disturbed sleep, most notably the degree of cognitive impairment and presence of comorbidities such as depression, agitation, and other behavioral disturbances commonly reported in $\mathrm{AD}$ patients. Thus, any associations, or lack thereof, may be obscured by the worse sleep and greater impairment that patients with severe AD inherently have.

Finally, only publications reporting specifically on AD patients were included and thus this review may have omitted data from studies on the burden of insomnia in $\mathrm{AD}$ patients which reported a population more broadly defined as dementia. Finally, the review and synthesis of the identified publications included only a qualitative review of the data and no further analyses were undertaken.

\section{CONCLUSIONS}

Insomnia/sleep disturbances confer a significant burden on both $\mathrm{AD}$ patients and caregivers and are an important risk factor for the institutionalization of patients. However, sleep and rhythm disturbances remain poorly characterized by clinicians and underresearched in this population, and no data were identified on the economic burden they may confer. Additional research is needed to fully quantify these clinical and economic burdens, especially given the large population at risk for AD. Furthermore, there is a paucity of data on effective treatments for insomnia in $\mathrm{AD}$ patients and the impact of treatment on clinical burden in patients and their caregivers.

The aging global population will increase the number of individuals at risk of developing $\mathrm{AD}$. Sleep disturbances, particularly insomnia, appear to exacerbate this risk, and most currently available pharmacotherapies for insomnia have not been studied sufficiently in $\mathrm{AD}$ patients; treatment guidelines advise against the use of many pharmacotherapies in older adults. Due to the impact of insomnia/sleep disturbances on AD risk and progression, and the associated patient and caregiver burden, there is a need to further evaluate the burden of disease in $\mathrm{AD}$ patients, investigate therapies targeted to this population, and determine whether treating insomnia and other sleep disorders may decrease the risk of developing $\mathrm{AD}$ and/or slow its progression.

\section{ACKNOWLEDGMENTS}

Medical writing assistance, under the direction of the authors, was provided by Ashley Enstone, Patrick Lavelle and Amy Sears of Adelphi Values PROVETM, in accordance with Good Publication Practice (GPP3) guidelines. This assistance was funded by Merck Sharp \& Dohme Corp., a subsidiary of Merck \& Co., Inc., Kenilworth, NJ, USA (MSD). Christopher Lines, PhD, and Alan Lipschitz, MD of MSD assisted with editing of the paper.

\section{FUNDING}

This study was supported by Merck Sharp \& Dohme Corp., a subsidiary of Merck \& Co., Inc., Kenilworth, NJ, USA.

\section{SUPPLEMENTARY MATERIAL}

The supplementary material is available in the electronic version of this article: https://dx.doi.org/ 10.3233/JAD-215324.

\section{REFERENCES}

[1] Urrestarazu E, Iriarte J (2016) Clinical management of sleep disturbances in Alzheimer's disease: Current and emerging strategies. Nature and Science of Sleep $\mathbf{8}, 21$.

[2] Lopez OL (2011) The growing burden of Alzheimer's disease. The American Journal of Managed Care 17(Suppl 13), S339-45.

[3] Kirson NY, Desai U, Ristovska L, Cummings AKG, Birnbaum HG, Ye W, et al. (2016) Assessing the economic burden of Alzheimer's disease patients first diagnosed by specialists. BMC Geriatrics 16, 138.

[4] Tractenberg RE, Singer CM, Cummings JL, Thal LJ (2003) The Sleep Disorders Inventory: An instrument for studies of sleep disturbance in persons with Alzheimer's disease. Journal of Sleep Research 12(4), 331-337.

[5] Sateia MJ, Buysse DJ, Krystal AD, Neubauer DN, Heald JL (2017) Clinical Practice Guideline for the Pharmacologic Treatment of Chronic Insomnia in Adults: An American Academy of Sleep Medicine Clinical Practice Guideline. Journal of Clinical Sleep Medicine 13(2), 307-349. 
[6] Guarnieri B, Adorni F, Musicco M, Appollonio I, Bonanni E, Caffarra P, Caltagirone C, Cerroni G, Concari L, Cosentino FII, Ferrara S, Fermi S, Ferri R, Gelosa G, Lombardi G, Mazzei D, Mearelli S, Morrone E, Murri L, Nobili FM, Passero S, Perri R, Rocchi R, Sucapane P, Tognoni G, Zabberoni S, Sorbi S (2012) Prevalence of Sleep Disturbances in Mild Cognitive Impairment and Dementing Disorders: A Multicenter Italian Clinical Cross-Sectional Study on 431 Patients. Dementia and Geriatric Cognitive Disorders 33(1), 50-58.

[7] Camargos EF, Pandolfi MB, Freitas MPD, Guimaraes RM, Quintas JL (2009) Sleep disorders in elderly patients with Alzheimer's disease and other dementias. Sleep Medicine 2, S8-S9.

[8] Pistacchi M, Gioulis M, Contin F, Sanson F, Marsala SZ (2014) Sleep disturbance and cognitive disorder: Epidemiological analysis in a cohort of 263 patients. Neurological Sciences 35(12), 1955-1962.

[9] Bubu OM, Brannick M, Mortimer J, Umasabor-Bubu O, Sebastiao YV, Wen Y, Schwartz S, Borenstein AR, Wu Y, Morgan D, Anderson WM (2017) Sleep, Cognitive impairment, and Alzheimer's disease: A Systematic Review and Meta-Analysis. Sleep 40(1).

[10] Peter-Derex L, Yammine P, Bastuji H, Croisile B (2015) Sleep and Alzheimer's disease. Sleep Medicine Reviews 19, 29-38.

[11] Shi L, Chen SJ, Ma MY, Bao YP, Han Y, Wang YM, Shi J, Vitiello MV, Lu L (2018) Sleep disturbances increase the risk of dementia: A systematic review and meta-analysis. Sleep Medicine Reviews 40, 4-16.

[12] Mander BA (2020) Local Sleep and Alzheimer's Disease Pathophysiology. Frontiers in Neuroscience 14(1008).

[13] Lam S, Macina LO (2017) Therapy Update for Insomnia in the Elderly. The Consultant pharmacist : The Journal of the American Society of Consultant Pharmacists 32(10), 610-622.

[14] American Geriatrics Society (2019) Updated AGS Beers Criteria ${ }^{\circledR}$ for Potentially Inappropriate Medication Use in Older Adults. Journal of the American Geriatrics Society 67(4), 674-694.

[15] Allegri RF, Sarasola D, Serrano CM, Taragano FE, Arizaga RL, Butman J, Lon L (2006) Neuropsychiatric symptoms as a predictor of caregiver burden in Alzheimer's disease. Neuropsychiatric Disease and Treatment 2(1), 105-110.

[16] Ancoli-Israel S, Gehrman P, Martin JL, Shochat T, Marler M, Corey-Bloom J, Levi L (2003) Increased light exposure consolidates sleep and strengthens circadian rhythms in severe Alzheimer's disease patients. Behavioral Sleep Medicine 1(1), 22-36.

[17] Baek MS, Han K, Koo Y, Choi BK, Na HK, Lyoo CH, Cho H (2019) Insomnia Increases the Risk of Alzheimer's Disease and Vascular Dementia: A Nationwide PopulationBased Study in South Korea. Alzheimer's and Dementia 15(7 Supplement), P696.

[18] Bianchetti A, Scuratti A, Zanetti O, Binetti G, Frisoni GB, Magni E, Trabucchi M (1995) Predictors of mortality and institutionalization in Alzheimer disease patients 1 year after discharge from an Alzheimer dementia unit. Dementia 6(2), 108-112.

[19] Bliwise DL, Hughes M, McMahon PM, Kutner N (1995) Observed sleep/wakefulness and severity of dementia in an Alzheimer's disease special care unit. Journals of Gerontology - Series A Biological Sciences and Medical Sciences 50(6), M303-M6.
[20] Brusco LI, Fainstein I, Marquez M, Cardinali DP (1999) Effect of melatonin in selected populations of sleepdisturbed patients. Biological Signals and Receptors 8(1-2), 126-131.

[21] Camargos EF, Louzada LL, Quintas JL, Naves JOS, Louzada FM, Nobrega OT (2014) Trazodone improves sleep parameters in Alzheimer disease patients: A randomized, double-blind, and placebo-controlled study. American Journal of Geriatric Psychiatry 22(12), 1565-1574.

[22] Camargos EF, Scoralick FM, Louzada LL, Quintas JL, Nóbrega OT (2015) Alzheimer's Disease and Sleep Disorders: A Descriptive Study of Actigraphic and Clinical Presentation Based on Neuropsychiatric Inventory. Austin Alzheimer's and Parkinson's Disease 2(1), 1019.

[23] Chew J, Abengana J, Ali N, Chan M, Tay L, Lim WS (2019) Self-Reported Sleep Duration as a Predictor of Cognitive Decline in Mild Cognitive Impairment (Mci) and Mild Alzheimer's Dementia (Ad). Alzheimer's and Dementia 15 (7 Supplement), P1185.

[24] Colenda CC, Cohen W, McCall WV, Rosenquist PB (1997) Phototherapy for patients with Alzheimer disease with disturbed sleep patterns: Results of a community-based pilot study. Alzheimer Disease and Associated Disorders 11(3), 175-178.

[25] de Oliveira FF, Bertolucci PH, Chen ES, Smith MAC (2014) Assessment of sleep satisfaction in patients with dementia due to Alzheimer's disease. Journal of Clinical Neuroscience 21(12), 2112-2117.

[26] Donaldson C, Tarrier N, Burns A (1998) Determinants of carer stress in Alzheimer's disease. International Journal of Geriatric Psychiatry 13(4), 248-256.

[27] Dowling GA, Hubbard EM, Mastick J, Luxenberg JS, Burr RL, Van Someren EJW (2005) Effect of morning bright light treatment for rest-activity disruption in institutionalized patients with severe Alzheimer's disease. International Psychogeriatrics 17(2), 221-236.

[28] Escudero JMS, Beltran J, Palacios A, Chimbi CM, Matallana D, Reyes P, Perez-Sola V, Santamaria-Garcia H (2019) Neuropsychiatric symptoms as predictors of clinical course in neurodegeneration. A longitudinal study. Frontiers in Aging Neuroscience 11(176).

[29] Garcia-Alberca JM, Lara JP, Cruz B, Garrido V, Gris E, Barbancho MA (2013) Sleep disturbances in Alzheimer's disease are associated with neuropsychiatric symptoms and antidementia treatment. Journal of Nervous and Mental Disease 201(3), 251-257.

[30] Gehrman PR, Connor DJ, Martin JL, Shochat T, CoreyBloom J, Ancoli-Israel S (2009) Melatonin fails to improve sleep or agitation in double-blind randomized placebocontrolled trial of institutionalized patients with Alzheimer disease. American Journal of Geriatric Psychiatry 17(2), 166-169.

[31] Gehrman P, Gooneratne NS, Brewster GS, Richards KC, Karlawish J (2018) Impact of Alzheimer disease patients' sleep disturbances on their caregivers. Geriatric Nursing (New York, NY) 39(1), 60-65.

[32] Grace JB, Walker MP, McKeith IG (2000) A comparison of sleep profiles in patients with dementia with lewy bodies and Alzheimer's disease. International Journal of Geriatric Psychiatry 15(11), 1028-1033.

[33] Hart DJ, Craig D, Compton SA, Critchlow S, Kerrigan BM, McIlroy SP, Passmore AP (2003) A retrospective study of the behavioural and psychological symptoms of mid and late phase Alzheimer's disease. International Journal of Geriatric Psychiatry 18(11), 1037-1042. 
[34] Hannesdottir K, Minkwitz M, Raudibaugh K, Vis P, Ackaert O, Alexander R (2013) A phase II safety and tolerability study to investigate the effect of AZD5213 on sleep in subjects with mild cognitive impairment and mild Alzheimer's disease. Alzheimer's and Dementia 1, P891-P2.

[35] Herring WJ, Ceesay P, Snyder E, Bliwise D, Budd K, Hutzelmann J, Stevens J, Lines C, Michelson D (2020) Polysomnographic assessment of suvorexant in patients with probable Alzheimer's disease dementia and insomnia: A randomized trial. Alzheimer's \& Dementia 16(3), 541-551.

[36] Ishikawa I, Shinno H, Ando N, Mori T, Nakamura Y (2016) The effect of memantine on sleep architecture and psychiatric symptoms in patients with Alzheimer's disease. Acta Neuropsychiatrica 28(3), 157-164.

[37] Kabeshita Y, Adachi H, Matsushita M, Kanemoto H, Sato S, Suzuki Y, Yoshiyama K, Shimomura T, Yoshida T, Shimizu H, Matsumoto T, Mori T, Kashibayashi T, Tanaka H, Hatada Y, Hashimoto M, Nishio Y, Komori K, Tanaka T, Yokoyama K, Tanimukai S, Ikeda M, Takeda M, Mori E, Kudo T, Kazui H. Sleep disturbances are key symptoms of very early stage Alzheimer disease with behavioral and psychological symptoms: A Japan multi-center cross-sectional study (J-BIRD). International Journal of Geriatric Psychiatry 32(2) (2017), 222-230.

[38] Kazui H, Yoshiyama K, Kanemoto H, Suzuki Y, Sato S, Hashimoto M, Ikeda M, Tanaka H, Hatada Y, Matsushita M, Nishio Y, Mori E, Tanimukai S, Komori K, Yoshida T, Shimizu H, Matsumoto T, Mori T, Kashibayashi T, Yokoyama K, Shimomura T, Kabeshita Y, Adachi H, Tanaka T (2016) Differences of behavioral and psychological symptoms of dementia in disease severity in four major dementias. PLoS ONE 11(8) (no pagination)(e0161092).

[39] Kim KD, Hong SC, Lee SY, Lee CT (2017) The impact of sleep disturbance to caregivers of alzheimer's disease. Sleep Medicine 40(Supplement 1), e160.

[40] La AL, Walsh CM, Neylan TC, Vossel KA, Yaffe K, Krystal AD, Miller BL, Karageorgiou E (2019) Long-Term Trazodone Use and Cognition: A Potential Therapeutic Role for Slow-Wave Sleep Enhancers. Journal of Alzheimer's Disease 67(3), 911-21.

[41] Lebrija P, Alarcon MF, Sosa-Ortiz AL, Acosta-Castillo GI, Ramirez-Santos R (2016) Association between sleep disorders and neuropsychiatric symptoms in Mexican patients with Alzheimer's disease at the national institute of neurology and neurosurgery of Mexico. Alzheimer's and Dementia 12(7 Supplement), P688-P90.

[42] Lee JH, Kim SJ, Lee SH, Suh IB, Jang J, Jhoo JH (2018) Changes in the sleep quality and caregiver burden by timed blue light in alzheimer's disease. Sleep 41(Supplement 1), A379-A 80 .

[43] Leger D, Elbaz M, Dubois A, Rio S, Mezghiche H, Carita P, Stemmelin J, Strauss M (2017) Alzheimer's disease severity is not significantly associated with short sleep: Survey by actigraphy on 208 mild and moderate Alzheimer's disease patients. Journal of Alzheimer's Disease 55(1), 321-331.

[44] Leng M, Yin H, Zhang P, Jia Y, Hu M, Li G, Wang C, Chen L (2020) Sleep Quality and Health-Related Quality of Life in Older People With Subjective Cognitive Decline, Mild Cognitive Impairment, and Alzheimer Disease. The Journal of Nervous and Mental Disease 20.

[45] Lukovits TG, McDaniel KD (1992) Behavioral disturbance in severe Alzheimer's disease: A comparison of family member and nursing staff reporting. Journal of the American Geriatrics Society 40(9), 891-895.
[46] McCarten JR, Kovera C, Maddox MK, Cleary JP (1995) Triazolam in Alzheimer's disease: Pilot study on sleep and memory effects. Pharmacology, Biochemistry and Behavior 52(2), 447-452.

[47] McCurry SM, Logsdon RG, Teri L, Gibbons LE, Kukull WA, Bowen JD, McCormick WC, Larson EB (1999) Characteristics of sleep disturbance in community-dwelling Alzheimer's disease patients. Journal of Geriatric Psychiatry and Neurology 12(2), 53-59.

[48] McCurry SM, Gibbons LE, Logsdon RG, Vitiello M, Teri L (2003) Training caregivers to change the sleep hygiene practices of patients with dementia: The NITE-AD project. Journal of Geriatric Psychiatry and Neurology 51(10), $1455-1460$.

[49] McCurry SM, Gibbons LE, Logsdon RG, Teri L (2004) Anxiety and nighttime behavioral disturbances. Awakenings in patients with Alzheimer's disease. Journal of Gerontological Nursing 30(1), 12-20.

[50] McCurry SM, Gibbons LE, Logsdon RG, Vitiello MV, Teri L (2005) Nighttime Insomnia Treatment and Education for Alzheimer's Disease: A randomized, controlled trial. Journal of the American Geriatrics Society 53(5), 793-802.

[51] McCurry SM, Vitiello MV, Gibbons LE, Logsdon RG, Teri L (2006) Factors associated with caregiver reports of sleep disturbances in persons with dementia. American Journal of Geriatric Psychiatry 14(2), 112-120.

[52] McCurry SM, Pike KC, Vitiello MV, Logsdon RG, Larson EB, Teri L (2011) Increasing walking and bright light exposure to improve sleep in community-dwelling persons with Alzheimer's disease: Results of a randomized, controlled trial. Journal of the American Geriatrics Society 59(8), 1393-1402.

[53] Meguro K, Meguro M, Tanaka Y, Akanuma K, Yamaguchi $\mathrm{K}$, Itoh M (2004) Risperidone is effective for wandering and disturbed sleep/wake patterns in Alzheimer's disease. Journal of Geriatric Psychiatry and Neurology 17(2), 61-67.

[54] Moran M, Lynch CA, Walsh C, Coen R, Coakley D, Lawlor BA (2005) Sleep disturbance in mild to moderate Alzheimer's disease. Sleep Medicine 6(4), 347-352.

[55] Mulin E, Zeitzer JM, Friedman L, Le Duff F, Yesavage J, Robert PH, David R (2011) Relationship between apathy and sleep disturbance in mild and moderate Alzheimer's disease: An actigraphic study. Journal of Alzheimer's Disease 25(1), 85-91.

[56] Okuda S, Tetsuka J, Takahashi K, Toda Y, Kubo T, Tokita S (2019) Association between sleep disturbance in Alzheimer's disease patients and burden on and health status of their caregivers. Journal of Neurology 266(6), 1490-500.

[57] Ownby RL, Saeed M, Wohlgemuth W, Capasso R, Acevedo A, Peruyera G, Sevush S (2010) Caregiver reports of sleep problems in non-Hispanic white, Hispanic, and African American patients with Alzheimer dementia. Journal of Clinical Sleep Medicine 6(3), 281-289.

[58] Ownby RL, Peruyera G, Acevedo A, Loewenstein D, Sevush S (2014) Subtypes of sleep problems in patients with alzheimer disease. American Journal of Geriatric Psychiatry 22(2), 148-156.

[59] Pang FC, Chow TW, Cummings JL, Leung VPY, Chiu HFK, Lam LCW, Chen QL, Tai CT, Chen LW, Wang SJ, Fuh JL (2002) Effect of neuropsychiatric symptoms of Alzheimer's disease on Chinese and American caregivers. International Journal of Geriatric Psychiatry 17(1), 29-34.

[60] Petrescu B, Vasile D, Vasiliu O, Mangalagiu A, Riga D, Riga S, Mitrache A, Simioniuc-Petrescu A (2019) Evaluation of trazodone and quetiapine in patients with Alzheimer's 
type dementia and sleep disturbance. European Neuropsychopharmacology 29(Supplement 1), S156.

[61] Ribeiro EB, Ramos CF, Spedo CT, Araujo RB, Carvalho Vale FA (2018) Sleep Disorders and Alzheimer's Disease: A Clinical Evaluation. Alzheimer's and Dementia 14(7 Supplement), P415.

[62] Scoralick FM, Louzada LL, Quintas JL, Naves JO, Camargos EF, Nobrega OT (2017) Mirtazapine does not improve sleep disorders in Alzheimer's disease: Results from a double-blind, placebo-controlled pilot study. Psychogeriatrics 17(2), 89-96.

[63] Shin HY, Han HJ, Shin DJ, Park HM, Lee YB, Park KH (2014) Sleep problems associated with behavioral and psychological symptoms as well as cognitive functions in Alzheimer's disease. Journal of Clinical Neurology 10(3), 203-209.

[64] Simoncini M, Gatti A, Quirico PE, Balla S, Capellero B, Obialero R, D'Agostino S, Sandri N, Pernigotti LM (2015) Acupressure in insomnia and other sleep disorders in elderly institutionalized patients suffering from Alzheimer's disease. Aging Clinical and Experimental Research 27(1), $37-42$.

[65] Singer C, Tractenberg RE, Kaye J, Schafer K, Gamst A, Grundman M, Thomas R, Thal LJ (2003) A multicenter, placebo-controlled trial of melatonin for sleep disturbance in Alzheimer's disease. Sleep 26(7), 893-901.

[66] Stahl SM, Markowitz JS, Papadopoulos G, Sadik K (2004) Examination of nighttime sleep-related problems during double-blind, placebo-controlled trials of galantamine in patients with Alzheimer's disease. Current Medical Research and Opinion 20(4), 517-524.

[67] Taemeeyapradit U, Udomittipong D, Tepparak N (2014) Characteristics of behavioral and Psychological Symptoms of Dementia, severity and levels of distress on caregivers. Journal of the Medical Association of Thailand 97(4), 423-430.

[68] Tractenberg RE, Singer CM, Kaye JA (2005) Symptoms of sleep disturbance in persons with Alzheimer's disease and normal elderly. Journal of Sleep Research 14(2), 177-185.

[69] Wade AG, Farmer M, Harari G, Fund N, Laudon M, Nir T, et al. (2014) Add-on prolonged-release melatonin for cognitive function and sleep in mild to moderate Alzheimer's disease: A 6-month, randomized, placebo-controlled, multicenter trial. Clinical Interventions in Aging 9, 947-961.

[70] Yin Y, Liu Y, Zhuang J, Pan X, Li P, Yang Y, Li YP, Zhao ZQ, Huang LQ, Zhao ZX (2015) Low-Dose Atypical Antipsychotic Risperidone Improves the 5-Year Outcome in Alzheimer's Disease Patients with Sleep Disturbances. Pharmacology 96(3-4), 155-162.

[71] Zhou G, Liu S, Yu X, Zhao X, Ma L, Shan P (2019) High prevalence of sleep disorders and behavioral and psychological symptoms of dementia in late-onset Alzheimer disease: A study in Eastern China. Medicine (United States) 98(50), e18405.

[72] Lai CK (2014) The merits and problems of Neuropsychiatric Inventory as an assessment tool in people with dementia and other neurological disorders. Clinical Interventions in Aging 9, 1051.

[73] van Someren EJW, Swaab DF, Colenda CC, Cohen W, McCall WV, Rosenquist PB (1999) Bright light therapy: Improved sensitivity to its effects on rest- activity rhythms in Alzheimer patients by application of nonparametric methods. Chronobiology International 16(4), 505-518.
[74] Ju YS, Videnovic A, Vaughn BV (2017) Comorbid Sleep Disturbances in Neurologic Disorders. Continuum (Minneapolis, Minn) 23(4), 1117-1131.

[75] David R, Zeitzer J, Friedman L, Noda A, O'hara R, Robert P, et al. (2010) Non-pharmacologic management of sleep disturbance in Alzheimer's disease. The Journal of Nutrition, Health \& Aging 14(3), 203-206.

[76] Capezuti E, Zadeh RS, Pain K, Basara A, Jiang NZ, Krieger AC (2018) A systematic review of non-pharmacological interventions to improve nighttime sleep among residents of long-term care settings. BMC Geriatrics 18(1), $1-18$.

[77] Snow AL, Loup J, Morgan RO, Richards K, Parmelee PA, Baier RR, et al. (2021) Enhancing sleep quality for nursing home residents with dementia: A pragmatic randomized controlled trial of an evidence-based frontline huddling program. BMC Geriatrics 21(1), 1-15.

[78] Lanctot KL, Amatniek J, Ancoli-Israel S, Arnold SE, Ballard C, Cohen-Mansfield J, Ismail Z, Lyketsos C, Miller DS, Musiek E, Osorio RS, Rosenberg PB, Satlin A, Steffens D, Tariot P, Bain LJ, Carrillo MC, Hendrix JA, Jurgens H, Boot B (2017) Neuropsychiatric signs and symptoms of Alzheimer's disease: New treatment paradigms. Alzheimer's and Dementia: Translational Research and Clinical Interventions 3(3), 440-449.

[79] Ferini-Strambi L, Galbiati A, Casoni F, Salsone M (2020) Therapy for Insomnia and Circadian Rhythm Disorder in Alzheimer Disease. Current Treatment Options in Neurology 22(2), 4.

[80] Overshott R, Byrne J, Burns A (2004) Nonpharmacological and pharmacological interventions for symptoms in Alzheimer's disease. Expert Review of Neurotherapeutics 4(5), 809-821.

[81] Defrancesco M, Marksteiner J, Fleischhacker WW, Blasko I (2015) Use of benzodiazepines in Alzheimer's disease: A systematic review of literature. International Journal of Neuropsychopharmacology 18(10).

[82] Dauvilliers Y (2007) Insomnia in patients with neurodegenerative conditions. Sleep Medicine 8(Suppl 4), S27-34.

[83] Kinnunen KM, Vikhanova A, Livingston G (2017) The management of sleep disorders in dementia: An update. Current Opinion in Psychiatry 30(6), 491-497.

[84] Song Y, Dowling GA, Wallhagen MI, Lee KA, Strawbridge WJ (2010) Sleep in older adults with Alzheimer's disease. Journal of Neuroscience Nursing 42(4), 190-198.

[85] McCleery J, Cohen DA, Sharpley AL (2016) Pharmacotherapies for sleep disturbances in dementia. Cochrane Database of Systematic Reviews 11(11), CD009178.

[86] McCurry SM, Ancoli-Israel S (2003) Sleep Dysfunction in Alzheimer's Disease and Other Dementias. Current Treatment Options in Neurology 5(3), 261-272.

[87] Vitiello MV, Borson S (2001) Sleep disturbances in patients with Alzheimer's disease: Epidemiology, pathophysiology and treatment. CNS Drugs 15(10), 777-796.

[88] Corey-Bloom J, Galasko D (1995) Adjunctive therapy in patients with Alzheimer's disease. A practical approach. Drugs and Aging 7(2), 79-87.

[89] Deschenes CL, McCurry SM (2009) Current treatments for sleep disturbances in individuals with dementia. Current Psychiatry Reports 11(1), 20-26.

[90] Herring WJ, Connor KM, Snyder E, Snavely DB, Zhang Y, Hutzelmann J, et al. (2017) Suvorexant in elderly patients with insomnia: Pooled analyses of data from phase III randomized controlled clinical trials. The American Journal of Geriatric Psychiatry 25(7), 791-802. 
[91] Moline M, Yardley J, Pinner K, Kumar D, Bsharat M, Kärppä M, et al. (2020) Efficacy and Safety of Lemborexant in Elderly Subjects with Insomnia Disorder: Pooled Analyses from SUNRISE-1 and SUNRISE-2 (1860). Neurology 94(15 Supplement), 1860.

[92] Moline M, Thein S, Bsharat M, Rabbee N, KemethoferWaliczky M, Filippov G, et al. (2021) Safety and Efficacy of Lemborexant in Patients With Irregular Sleep-Wake Rhythm Disorder and Alzheimer's Disease Dementia: Results From a Phase 2 Randomized Clinical Trial. The Journal of Prevention of Alzheimer's Disease 8(1), 7-18.

[93] Janto K, Prichard JR, Pusalavidyasagar S (2018) An Update on Dual Orexin Receptor Antagonists and Their Potential Role in Insomnia Therapeutics. Journal of Clinical Sleep Medicine 14(8), 1399-1408.

[94] Gagnon JF, Petit D, Fantini ML, Rompré S, Gauthier S, Panisset M, et al. (2006) REM sleep behavior disorder and REM sleep without atonia in probable Alzheimer disease. Sleep 29(10), 1321-1325.
[95] Wang P, Wing YK, Xing J, Liu Y, Zhou B, Zhang Z, et al. (2016) Rapid eye movement sleep behavior disorder in patients with probable Alzheimer's disease. Aging Clinical and Experimental Research 28(5), 951-957.

[96] Emamian F, Khazaie H, Tahmasian M, Leschziner GD, Morrell MJ, Hsiung GY, et al. (2016) The Association Between Obstructive Sleep Apnea and Alzheimer's Disease: A MetaAnalysis Perspective. Frontiers in Aging Neuroscience 8, 78 .

[97] Brzecka A, Leszek J, Ashraf GM, Ejma M, Ávila-Rodriguez MF, Yarla NS, et al. (2018) Sleep Disorders Associated With Alzheimer's Disease: A Perspective. Frontiers in Neuroscience 12, 330. 